\title{
ESTÉTICA CHANCAY DESDE LA ARQUITECTURA. UNA MIRADA TIPOLÓGICA ESPACIAL
}

\section{CHANCAY AESTHETICS FROM AN ARCHITECTURAL POINT OF VIEW. A SPATIAL TYPOLOGICAL PERSPECTIVE}

Miguel Guzmán JuárezaA \& Jorge Carlos Alvino Loli

Identificamos y explicamos las características estéticas de la arquitectura chancay (900-1533 DC), entendiendo que, sus elementos formales tienen una expresión tipológica particular. La investigación se centra en el estudio de los principios de diseño chancay manifestados en sus edificios y ciudades, en los elementos tipológicos o expresiones decorativas asociadas resultantes, que otorgan carácter al espacio, considerando diversos niveles de análisis, tanto formales, funcionales como simbólicos. Interesa "leer" las posibles correspondencias conceptuales entre las artesanías y la arquitectura, como partes consecuentes de ciertas lógicas de pensamiento andino que estarían expresando una estética particular chancay.

Palabras clave: Chancay, Estética, Arquitectura, Diseño, Relieves, Enlucidos.

We identify and explain the aesthetic characteristics of chancay architecture (900-1533 AC), in the understanding that formal elements possess a particular typological expression. This research focuses on the study of the chancay design principles manifested in their buildings or cities, and on the other, on the associated resulting typological elements, or decorative expressions, that give character to space, considering both formal, functional and symbolic levels of analysis. It is interesting to "read" the possible conceptual correspondences between crafts and architecture, as resulting from certain logic of Andean thought, which would express a particular chancay aesthetics.

Keywords: Chancay, Aesthetics, Architecture, Design, Reliefs, Plastering.

\section{INTRODUCCIÓN. SOBRE LAS CUALIDADES ESTÉTICAS}

El carácter estético de los objetos y de las acciones humanas está definido por la sensibilidad (aesthetic) o por la sensorialidad de las personas, sea individualmente como una experiencia directa o colectivamente por grupos sociales, los que han construido una tradición cosmológica de la existencia a partir de sistemas de convenciones. Sin embargo, una carga interpretativa sobre la arquitectura está dada por una visión occidental -desde la historia, la teoría o la crítica- que, generalmente, ha enfatizado o ha querido establecer un discurso universal en el que ella debería mostrar atributos artísticos que se acerquen a una "belleza" ideal, ligada a la perfección de las formas y a un deleite espiritual. Por otro lado, desde un entendimiento concreto, objetivo y crítico, la arquitectura es, sobre todo, un proceso de producción social que se sustenta en su utilidad (Ludeña 1997, 2001). Partiendo de una visión contemporánea, se plantea una mirada, es decir, una reflexión gestada a partir de los procesos perceptuales y que distingue los atributos estéticos de la producción arquitectónica de las

\footnotetext{
A Miguel Guzmán Juárez, Universidad Peruana de Ciencias Aplicadas UPC. Lima, Santiago de Surco. E-mail: quillca@hotmail.com

B Jorge Carlos Alvino Loli, Universidad Nacional Mayor de San Marcos unMsm. Lima. E-mail: jc_alvino@hotmail.com
} 
sociedades desarrolladas en el área conocida actualmente como los Andes Centrales, específicamente la Chancay. Desde ahí es posible entender y postular considerando las formas particulares de elaboración y expresión de sus muros -que son los elementos más claros y concretos en la definición de los espacios- que se convierten en soportes, no una "valoración", sino una reevaluación de aquellas cualidades estéticas propias de los objetos elaborados por las personas de esta sociedad, ${ }^{2}$ tratando de acercarse a comprender su cosmovisión.

En ese marco, se reconoce el riesgo de la mediación temporal en la interpretación o en la posible valoración de las obras que, actualmente, en muchos casos, se hallan deterioradas y sin el contexto social al que sirvieron. Sin embargo, las concepciones acerca del mundo fueron definitivamente otras y diferentes en el momento de contacto entre lo andino y lo occidental (Silva 2004), ${ }^{3}$ y contemporáneamente, el mundo globalizado ha construido, además, otra nueva estética: la de la imagen, la tecnología y la simultaneidad que, en diferentes medidas, afecta la forma actual de evaluar el pasado.

En cuanto a los objetos culturales o artesanías chancay, ${ }^{4}$ por ejemplo en su cerámica y en su textilería, se advierten modelos y características específicas que las identificarían: "chinos" y "cuchimilcos" para el primer caso, y textiles pintados o las famosas "muñecas" para el segundo, las que fueron expresiones de dicha sociedad, divulgadas y reconocidas a partir de mirarlas desde otra "estética", no ya la occidental ligada a la belleza de las formas, sino a lo sugerente de un mundo mítico de imágenes y símbolos como recreaciones de la existencia.

La cerámica producida por ellos ha sido reconocida y estigmatizada como "negro sobre blanco", en cuyas superficies se advierte el trazo de la tonalidad oscura (marrón) sobre el fondo claro (crema), con los cuales se conjugan y definen elementos que complementan la forma del soporte. En todo caso, hay una apuesta persistente por un criterio de dualidad. Allí, el trazo suelto o espontáneo o sus delineamientos sin una rigurosidad geométrica occidental, fueron causa de prejuicios que no valoraban sus "rápidas" expresiones creativas, las que felizmente han sido superadas junto al entendimiento y divulgación del "arte primitivo", mientras que su textilería adquiere una variedad de soportes, técnicas, formas, motivos y diseños con cromatismos diversos. Así, en 1998 se realizó en el Museo de Arte de Lima una exposición denominada "Contemporaneidad del arte Chancay, ${ }^{5}$ que buscó justamente revalorar una estética especial, rescatando los elementos particulares y sugerentes, y sus creativos diseños en sus diferentes expresiones ya señaladas. Las cualidades estéticas de aquellos objetos están ligadas a una recreación del territorio andino en cuanto paisaje simbólico construido y al sentido de admiración o asombro frente a los fenómenos naturales, que devino en estructuras de pensamiento, ciertamente particulares en cada momento histórico, pero que al mismo tiempo lograban continuidad en sus transformaciones, recreaciones y permanencias y, desde la particular mirada de hoy, se podría considerar como pensamiento andino. ${ }^{6}$

Sin embargo, su arquitectura ha permanecido olvidada, ignorada y destruida sistemáticamente. A pesar de ello, a partir de las evidencias materiales se confirma la existencia de un corpus arquitectónico que merece ser registrado e interpretado. Se postula que sería posible interpretar esos muros como "textos", que presentaron recurrencias y delicados trabajos jerarquizando los espacios y los edificios, y que fueron parte de un paisaje mayor del territorio interpretado simbólicamente.

La metodología aplicada considera tres momentos diferenciados: a) en primer lugar, la información utilizada se basa y se ha construido desde el contacto con fuentes primarias, como levantamientos arquitectónicos precisos y el registro fotográfico aplicado a los edificios analizados; b) en un segundo momento se plantea la formulación de principios de diseño a partir de la organización espacial de los edificios chancay; y c) se ha procedido al análisis formal estilístico donde se consideran las cualidades físicas de la obra y su organización: como la proporción, estructuras de formación, iconografía y técnicas de representación, una tipología particular de los elementos arquitectónicos chancay. En este trabajo se han incluido dos estudios aplicados a dos edificios específicos chancay: el palacio de La Bandurria y el edificio con rampa central en Pisquillo Chico (ERC), ambos casos representativos de la arquitectura chancay y distantes uno del otro apenas por cinco kilómetros en el valle bajo del río Chancay (Lima, Perú).

\section{ASENTAMIENTOS CHANCAY. ANTECEDENTES}

Esta sociedad tuvo su área nuclear en el valle bajo y medio del río Chancay (Provincia de Huaral, Lima; fig. 1) y en Huaura, pero su influencia llegó también hasta 


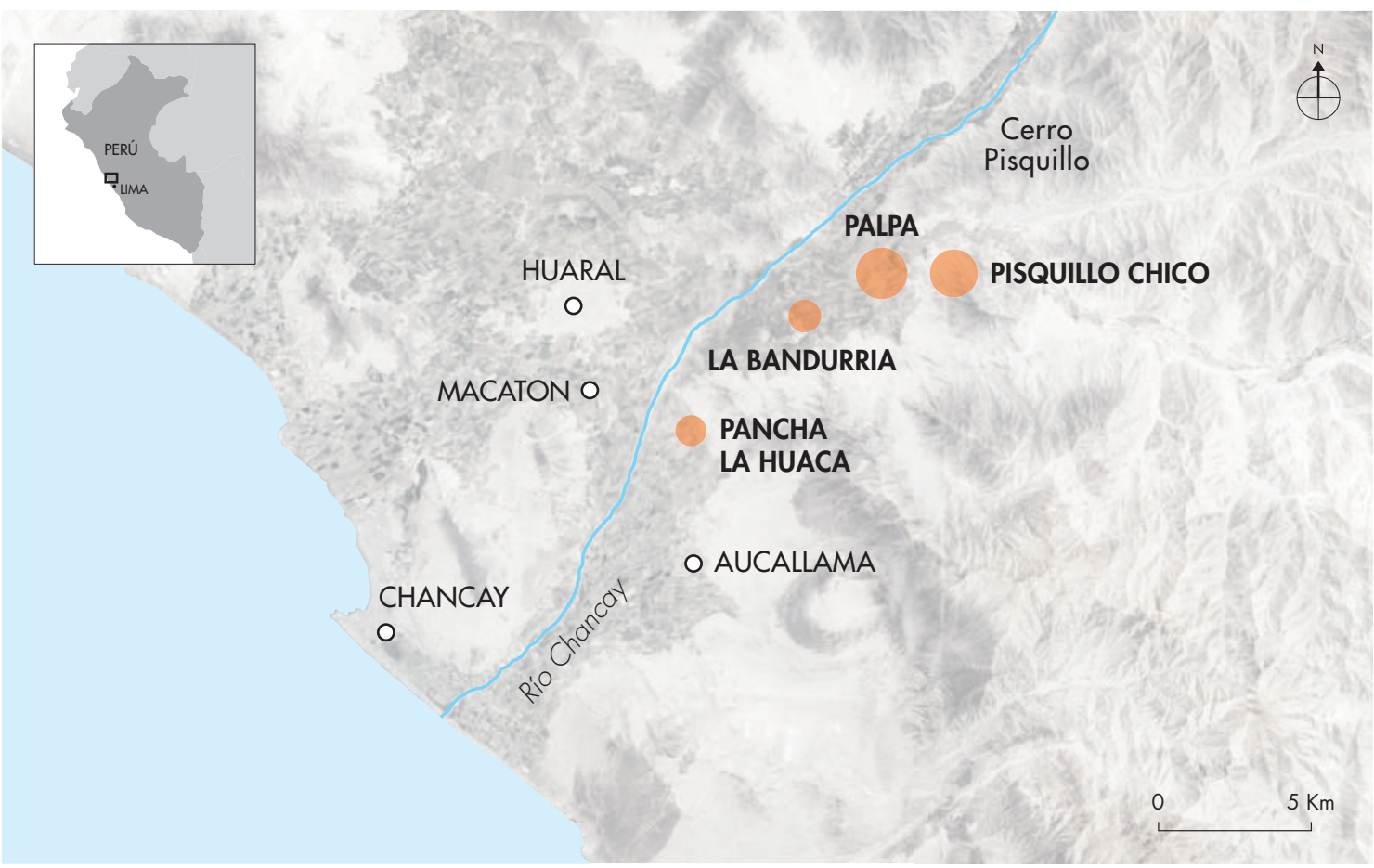

Figura 1. Ubicación de algunos sitios en el valle bajo del río Chancay y emplazamiento del valle mismo en el Perú. Figure 1. Sites located in the valley down the Chancay river and location of the valley in Peru.

el valle del río Supe por el norte y hasta los valles de los ríos Chillón y Rímac por el sur. Desarrolló sistemas de asentamientos complejos, con emplazamientos dentro de una lógica de la sostenibilidad, el intercambio y la complementariedad. Construyeron grandes centros urbanos o "ciudades" donde conjugaron zonas residenciales, administrativo-ceremoniales, y extensas áreas funerarias, en las que se desarrolló una especial arquitectura para la "muerte" (grandes "cementerios" hoy totalmente huaqueados o disturbados). También existen asentamientos menores y edificios aislados de carácter ceremonial, todos en una relación con el contexto: un paisaje cultural sacralizado. Entre los sitios más importantes y reconocidos están, en el valle de Huaura: Cerro Colorado, Hualmay y Vilcahuaura; en el valle de Chancay: Laure, Pisquillo Chico, Portillo, Saume, Lumbra, Pancha La Huaca (hoy inexistente), Macatón y La Bandurria entre otros, que demuestran la complejidad del fenómeno urbano; y en el valle de Chillón: Macas, Trapiche y Guarabí.

Se sabe de ellos a partir de algunas importantes investigaciones: prospecciones, análisis de materiales recuperados, o clasificación tipológica de los objetos culturales, y en menor grado de alguna excavación arqueológica sistemática. Fueron principalmente dos personajes quienes profundizaron en el conocimiento de la cultura Chancay. El primero de ellos fue Horkheimer, quien a partir de la década de 1960 ponderó la importancia de dicha antigua sociedad (Horkheimer 1963), dirigiendo la Misión Arqueológica Chancay. Hacia finales de la década de 1980, Krzanowski dirigió la Expedición Científica Polaca a los Andes, logrando publicar Estudios sobre la cultura Chancay, Perú (Krzanowski 1991), uno de los principales textos para comprender su complejidad. Hubo después algunos estudios sobre casos puntuales, como por ejemplo, el trabajo de Cornejo sobre "La sociedad prehispánica Chancay a través de la muerte" (Cornejo 1999), y Carlos Alvino, que registra algunas características de los asentamientos en "Arquitectura Chancay. Conjuntos de edificios con rampa central" (Alvino 2013). Por último, un significativo aporte sustentado en el registro de campo de diferentes asentamientos y edificios chancay, es el libro publicado recientemente por el autor, Arquitectura Chancay. Espacios rituales del tiempo sagrado (Guzmán 2016). 


\section{SOBRE LA ARQUITECTURA Y LOS PRINCIPIOS DE DISEÑO}

En los principales asentamientos chancay se incorpora un patrón arquitectónico definido como "edificio con rampa"8 (Alvino 2013; Guzmán 2015, 2016): la articulación de un ingreso frontal, un patio longitudinal, una rampa central y plataformas superpuestas, a partir de un eje de simetría axial; es decir, la conexión por medio de la rampa entre dos entidades: un volumen compacto (plataforma) y un espacio vacío (patio), de tal manera que se podría establecer un sistema de dualidad y complementariedad. Si bien existen ciertas variaciones dimensionales en algunos casos, se advierte una composición con una proporcionalidad común a todos, que les permite su identificación y pertenencia. Ese grado de percepción y de elaboración del diseño y su materialización formal consciente, permiten definir ya una primera entrada a la "estética chancay" desde la arquitectura; es decir, un sistema de proporción espacial o geométrica alargada, en referencia a la escala humana, en donde dicha percepción del espacio interior incorpora una sensación de cobijo por el alcance visual hacia los muros adyacentes y no de mayor amplitud (que sí se da, por ejemplo, en los edificios con rampa de Pachacamac, o los patios con rampa de Chan Chan). Al mismo tiempo, la organización del edificio con rampa muestra el manejo de criterios referidos al sistema de pensamiento ya aludido, como la dualidad (patio abajo-recinto plataforma arriba, doble patio con rampa central), la tripartición (división en tres unidades arquitectónicas, tres niveles diferenciados en plataformas, tres tipos de rampas), y la simetría (ejes de organización) e inversión del orden (patios con rampa en sentido contrario). Estos criterios señalan una manera especial de construir simbólicamente la experiencia del espacio, como se verá a continuación. Como ejemplo, se han escogido dos sitios de características arquitectónicas sumamente relevantes para postular la existencia de dichos criterios de diseño: Pisquillo Chico y La Bandurria.

Acerca del carácter funcional o simbólico de los edificios con rampa se han propuesto algunas hipótesis que es pertinente repasar, a partir de los estudios en el santuario de Pachacamac:

a) Edificios de función religiosa. Esta propuesta implica que los edificios fueron construidos y utilizados por grupos sociales foráneos al asentamiento de Pachacamac, pero dependientes de su deidad principal (Jiménez
1985). De ello se desprende que, durante el Período Intermedio Tardío y antes de la llegada del fenómeno Tawantinsuyu a la Costa Central, el culto a Pachacamac ya estaba ampliamente expandido y producto de lo mismo los edificios vinculados se difundieron. Jiménez denomina a este edificio Templo Provincial.

b) Edificios de función residencial palaciega. Función palaciega durante el Intermedio Tardío y función de culto para los peregrinos de distantes regiones del Tawantinsuyu durante el Horizonte Tardío (Eeckhout 2004). La propuesta principal indica que el edificio fue construido y funcionó como palacio de un personaje con autoridad local (quizá el curaca) quien a su muerte fue enterrado allí mismo implementando su tumba y, una vez convertido en mallqui, era considerado como el ancestro directo de un grupo humano que sacralizaría por extensión la momia, el espacio funerario y todo el edificio. Temporalmente, los conjuntos no funcionaron simultáneamente, sino que fueron abandonados uno tras otro, por lo que la configuración urbana de Pachacamac duró mucho tiempo. Sin embargo, esta función no debió ser permanente sino eventual (celebraciones o eventos sociales), para lo cual no se necesitaría grandes recintos.

En cualquier caso, se trata de un patrón arquitectónico que, al repetirse, adquiere sustanciales connotaciones simbólicas y se instaura en la memoria social, de tal manera que a través de generaciones se construye una estética en esa relación constante de elementos, sobre todo el de la rampa y su sentido de articulación entre lo de arriba y lo de abajo.

\section{Pisquillo Chico. El edificio con rampa central (ERC)}

Pisquillo Chico es un gran centro urbano multifuncional con una extensión de más de 30 hectáreas, y se ubica protegido por una cadena de cerros eriazos que dan inicio a la quebrada de Orcón, en la margen izquierda del río Chancay y cerca de él. Destaca su sector nuclear, distinguible por su monumentalidad relativa y su trazado proporcionado, donde existen hasta 15 conjuntos de edificios con rampa (Alvino 2013), organizados en algunos casos en parejas. Se distinguen dos conjuntos edificatorios por su mayor magnitud, denominados edificios con rampa 1 y 2 , dispuestos, respectivamente, al este y oeste de una gran plaza cuadrangular. Si se traza un eje axial por dicha plaza, se comprueba que la orga- 
nización de cada uno de los dos edificios corresponde a un desarrollo por medio de simetría especular, de lo que se desprende otro criterio de diseño, conceptualmente referido a yanantin: paridad a partir de un eje de simetría, que al mismo tiempo es la expresión de la dualidad y la inversión. Todo el sector se emplaza sobre una gran terraza formada por el terreno bajo de la quebrada, la que ha sido ha sido nivelada y reforzada lateralmente hacia el lado norte, de tal manera que mantiene una diferencia de nivel de casi siete metros con respecto al terreno agrícola inmediato. La accesibilidad a este sector, y por consiguiente a los dos conjuntos edificatorios, se realizaría a partir de un camino amurallado orientado de este-oeste.

El diseño de cada conjunto de edificios con rampa central corresponde a un modelo tripartito. Está constituido por tres unidades edificatorias longitudinales, paralelas y yuxtapuestas independientes, cuyos ejes se orientan en dirección norte-sur y están articuladas por pasajes o "canales" de circulación. Se encuentran asociadas y organizadas dentro de una limitante espacial que es un muro perimetral que encierra un área rectangular, en donde además existen patios y áreas abiertas complementarias.

\section{a) Edificio I o Unidad A (patio con rampa central):}

Patio. Unidad espacial de planta rectangular alargada (proporcionada de 3 a 1), no techada y delimitada físicamente por altos muros continuos. Posee un vano de ingreso ubicado en el eje central y opuesto a la rampa central, y otro vano en la parte media de un muro lateral, que comunicaba con las otras unidades. Debido a su dimensionamiento es el espacio mayor de todo el conjunto pudiendo albergar concentración de individuos.

Plataformas. Formas volumétricas elevadas cuya conformación exterior define un escalonamiento, generalmente con tres gradas de contención, que perceptualmente debió generar una dinámica especial y espacial. Son recintos de planta rectangular rellenados con diversos materiales y cubiertos con delgados pisos. La altura es variable alcanzando los seis metros, además, el ascenso entre plataformas se logra a partir de rampas ubicadas en el eje central, insertas o exentas, cuyo sentido de asenso es de norte a sur.

Recinto superior. Ubicado en la parte alta de las plataformas y en el extremo opuesto del ingreso al patio, se encuentra cercado en todos sus lados, a excepción del que lo vincula con el patio mismo, por un muro pintado en sus paredes internas. La última plataforma, la que probablemente estuvo techada por una cobertura ligera e inclinada, ${ }^{9}$ no posee rampa y quizás, por esta razón, pueda ser considerada "banqueta", y sobre la misma, en el eje central destaca un pequeño volumen adosado a modo de "altar".

Recintos posteriores. Son una serie de recintos, sin aparente cobertura, que se distribuyen complementariamente entre los edificios y el muro perimetral a modo de patios alargados.

\section{b) Edificio II o unidad B (patio con doble banqueta):}

Patio con doble banqueta. De planta rectangular alargada, las banquetas se disponen adosadas a los dos muros longitudinales y perimetrales y dejan un área de circulación central igual de ancha que las banquetas mismas. Inmediato a su acceso, hacia un costado, se encuentra generalmente una mesa de granito.

Plataforma con rampa lateral. Elemento volumétrico (plataformas de baja altura) al cual se accede por una rampa baja y adosada lateralmente a una de las banquetas.

Recintos superiores. En la parte superior de las plataformas y hacia ambos lados se ubican pequeños recintos que cierran la forma de $\mathrm{U}$ abierta hacia la plaza.

\section{c) Edificio III o unidad C (patio con rampa central invertida):}

Es el edificio más restringido, emplazado generalmente al centro del conjunto, al que se accede a partir de la anterior unidad y un vano central. De menores dimensiones que la unidad $\mathrm{A}$, pero de idéntica organización, posee toda su orientación en sentido invertido, es decir, la rampa asciende de sur a norte.

\section{d) Ejes de circulación o canales espaciales:}

Denominados generalmente pasajes o pasadizos. Pueden distinguirse dos niveles de circulación: canales a bajo nivel y canales elevados. Las del tipo elevado (por sobre el nivel del piso) permiten vincular los recintos superiores de las unidades $\mathrm{A}$ y $\mathrm{C}$, que poseen vanos comunicantes, a través de una circulación siguiendo una ruta zigzagueante, que define una forma de $S$ invertida, 


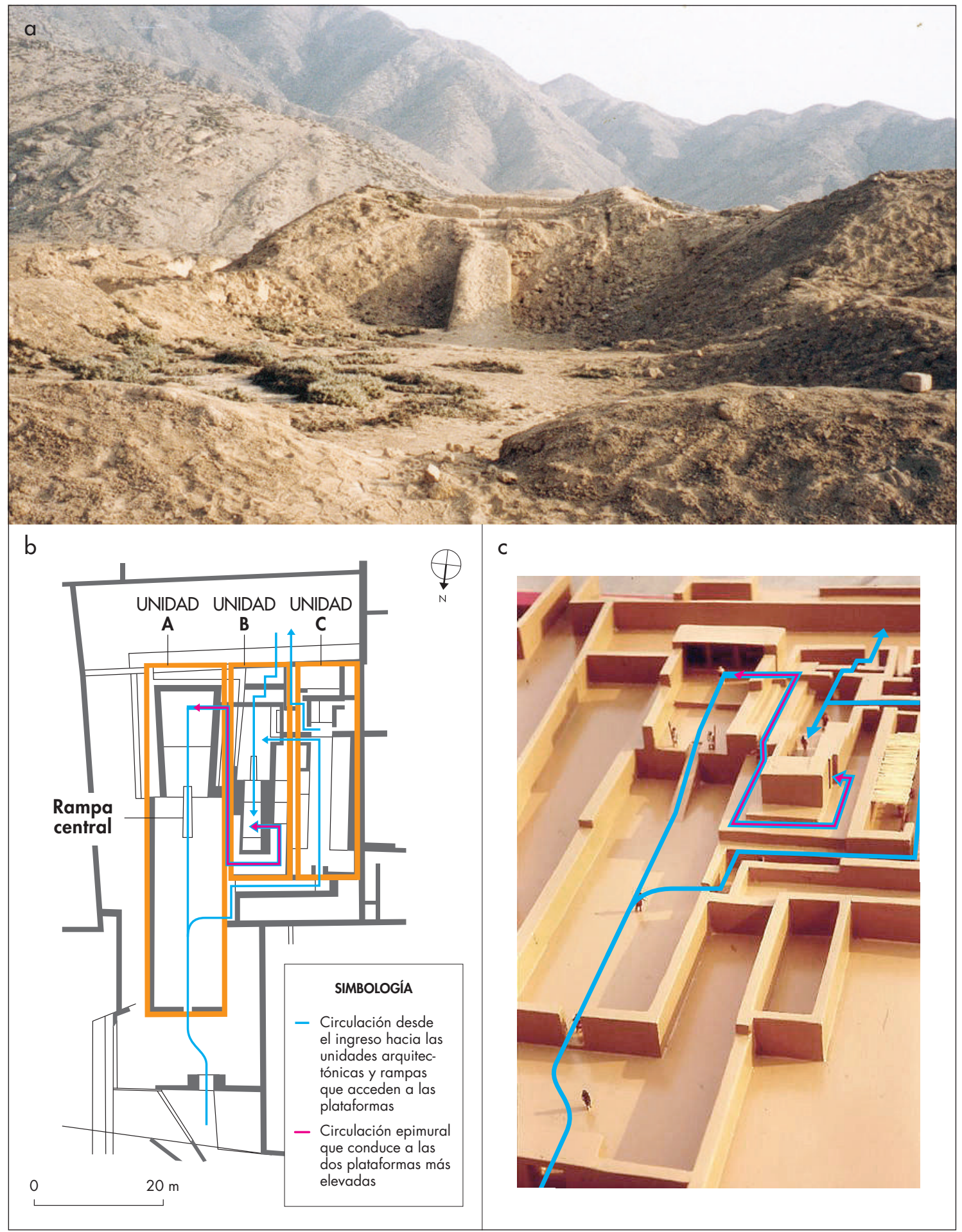

Figura 2. a) Edificio con rampa central en Pisquillo Chico. (Fotografía: Jorge Alvino); b) plano con subdivisión y circulaciones (Guzmán 2015: 22); c) maqueta de recomposición del mismo edificio (elaborada por Alvino en el año 2000. Guzmán 2016: 227, 263). Figure 2. a) Building with central ramp in Pisquillo Chico. (Photograph: Jorge Alvino); b) plan with subdivisions and roads (Guzmán 2015: 22); c) reconstitution of the same building (made by Alvino, 2000. Guzmán 2016: 227, 263). 


\section{CONJUNTO TRIPARTITO DE EDIFICIO CON RAMPAS}

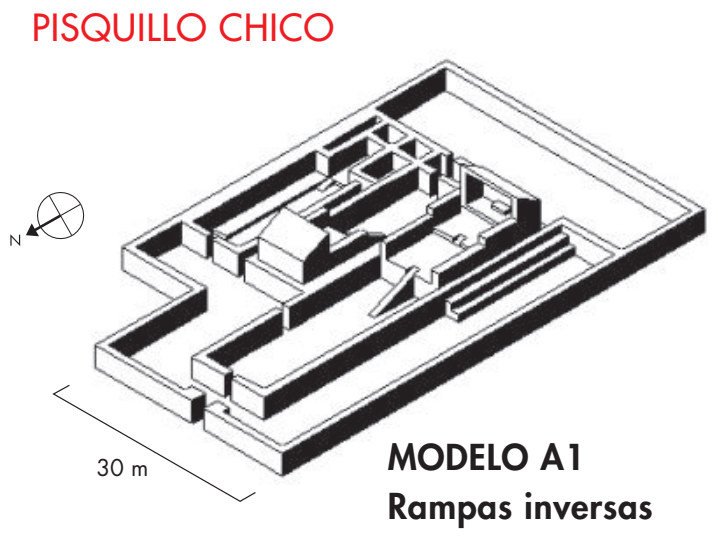

Planta modulada

Estructura formal
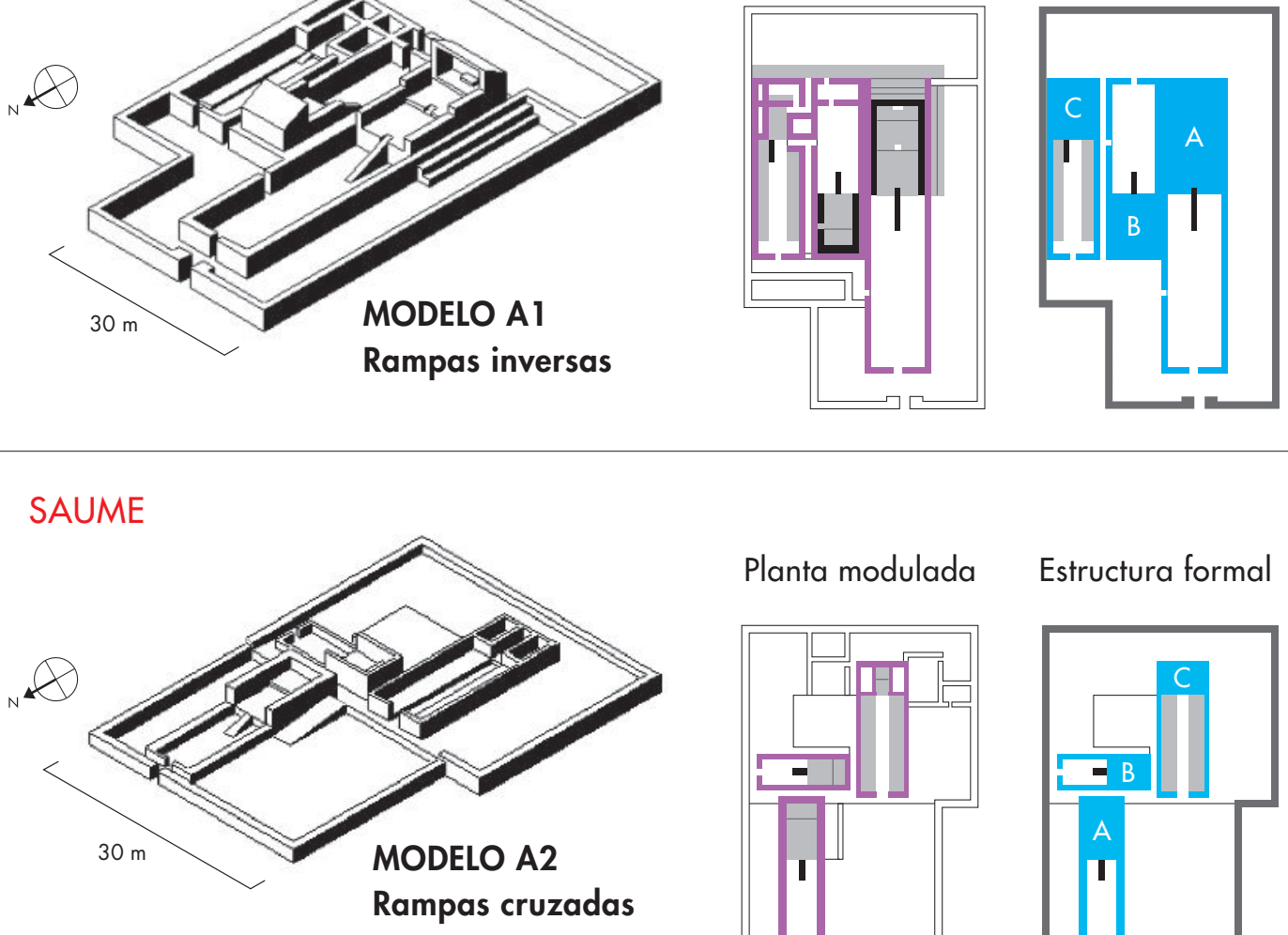

Planta modulada

Estructura formal
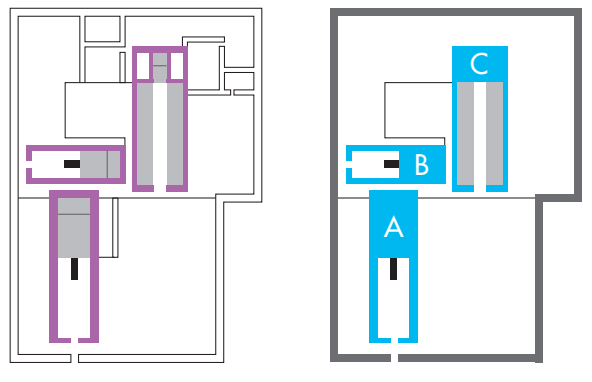

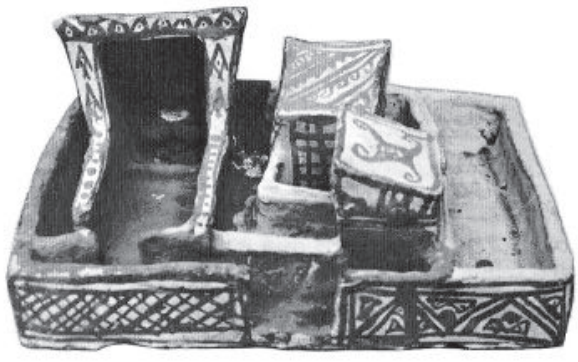

Maqueta modelada en arcilla con decoración blanco sobre negro

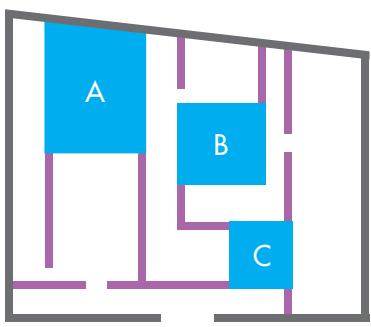

Planta de un conjunto tripartito A2

Figura 3. Interpretación arquitectónica del edificio con rampa en Chancay. (Elaboración propia sobre la propuesta de Alvino 2013: 174). Fotografía de modelo de arcilla (Wurster 1982: 260-261, fig. 18). Figure 3. Architectural interpretation of the building with ramp in Chancay. (Made by the authors based on Alvinos' 2013: 174 proposal). Photograph of the clay model (Wurster 1982: 260-261, fig. 18). 
de tal manera que la propia circulación se convierte en una forma espacial, un ícono estético que recuerda cierta iconografía de los textiles que aluden a la articulación y la complementariedad. En este caso se postula la utilización del criterio de tinkuy, o lugar de encuentro entre opuestos complementarios; y al mismo tiempo, las unidades A y C estarían organizadas desde un eje de simetría yanantin, con una inversión en el orden de los elementos constitutivos (Guzmán 2015).

\section{La Bandurria: vanos y alternancias}

El edificio La Bandurria (fig. 4) se asienta sobre la ladera de un cerro del mismo nombre. Horkheimer (1965: 47) llamó "templete" a dicho edificio. Su configuración en planta corresponde a una secuencia longitudinal de tres grandes recintos rectangulares dispuestos uno después del otro en dirección del eje este-oeste y se construyó usando el sistema de tapias, con algunos sectores de adobes. Hacia el frente de su lado norte, un extenso cerco escalonado que se adapta al relieve del cerro delimita una gran área abierta cuadrangular, y continúa por el frente oeste y luego por el sur, creando una envolvente rectangular que encierra a la plataforma principal.

\section{Nichos escalonados}

El detalle simbólico más importante del edificio se ubica en el muro norte del recinto oeste: la secuencia de los nichos escalonados. El recinto se encuentra desnivelado por deterioro general del relleno interno y la gran mayoría de sus muros perimetrales han colapsado, pero aún se mantiene en pie la esquina noroeste.

El muro norte posee una serie de nichos de particular trazado: su alzado presenta un perfil trapezoidal escalonado (fig. 5), y su diseño es un módulo repetitivo con características diferenciadas: el primer nicho va desde la base menor hacia la mayor y se encuentra cerrado (no traspasa el muro de tapial, es decir, sería un nicho), el siguiente es escalonado desde su base mayor hacia la menor y se encuentra abierto (traspasa el muro, sería un vano). Este ritmo se repite hacia la derecha sumando actualmente una cantidad de cinco vanos (quizás seis) que siguen este diseño dual. Es posible que todo el muro haya tenido este tipo de tratamiento, por lo que, de acuerdo con las medidas y proporciones de los nichos y la longitud total de la base del muro, pudieron sumar un total de 17 nichos (ocho abiertos y nueve cerrados) que pudieron ordenarse como dos cuatriparticiones y tres triparticiones, siendo interesante la asociación tripartita con la elevación del vano abierto y la división interior del edificio mismo. De acuerdo con el registro realizado en el alzado mismo de los nichos escalonados, la muestra conserva el sistema de proporciones y ordenamiento existente en la planta del edificio, que es la de a/2 y a $/ 3$, en donde $a$ es la unidad (figs. 4 y 5 ) que corresponde aproximadamente -dentro de nuestro sistema actual de medidas- a $60 \mathrm{~m}$ en el caso del edificio y $60 \mathrm{~cm}$ en el caso del nicho escalonado. Esta relación entre el edificio y los nichos es sugerente, pues permite asociar diferentes niveles de diseño arquitectónico y sugerir una propuesta, sino integral y contemporánea, al menos correspondiente.

Este trabajo murario es un rasgo significativo de la importancia de los edificios y su jerarquía. Su presencia no es común en los sitios chancay del valle, aunque sí existe en otros valles que tienen comprobada presencia del Tawantinsuyu, es decir, ocupaciones del Horizonte Tardío (1470-1533 DC); por ejemplo, en Tambo Colorado (Pisco), Ungará e Incahuasi (Cañete), Uquira (Asia), etc. Este podría ser un rasgo arquitectónico en los edificios más importantes construidos durante la expansión de la sociedad quechua en la costa, lo cual propondría a La Bandurria como un sitio administrativo cusqueño en el valle bajo del río Chancay. Un detalle interesante es la representación de este rasgo arquitectónico en una vasija Chimú, además con motivos de dos felinos sujetando a un hombre (fig. 5), quizás una pieza de cerámica manufacturada ya en el siglo XVI, cuando las interrelaciones ideológicas en la Costa Central adquirieron una nueva connotación con la intervención cusqueña. Es también interesante que esta representación incluya la figura completa, es decir una forma geométrica de 12 lados internos, aunque su interior esté invertido respecto del que encontramos en el edificio de nuestro análisis, es decir vacío.

\section{Nichos cuadrangulares}

El recinto central tiene una proporción alargada en el eje norte-sur y se caracteriza por la conformación y diseño de su muro este, que colinda con el pasaje central norte-sur. En realidad -a partir del punto donde se da un ingreso desde el pasaje señalado- se trata de un gran doble muro de tapial, o dos muros adosados 


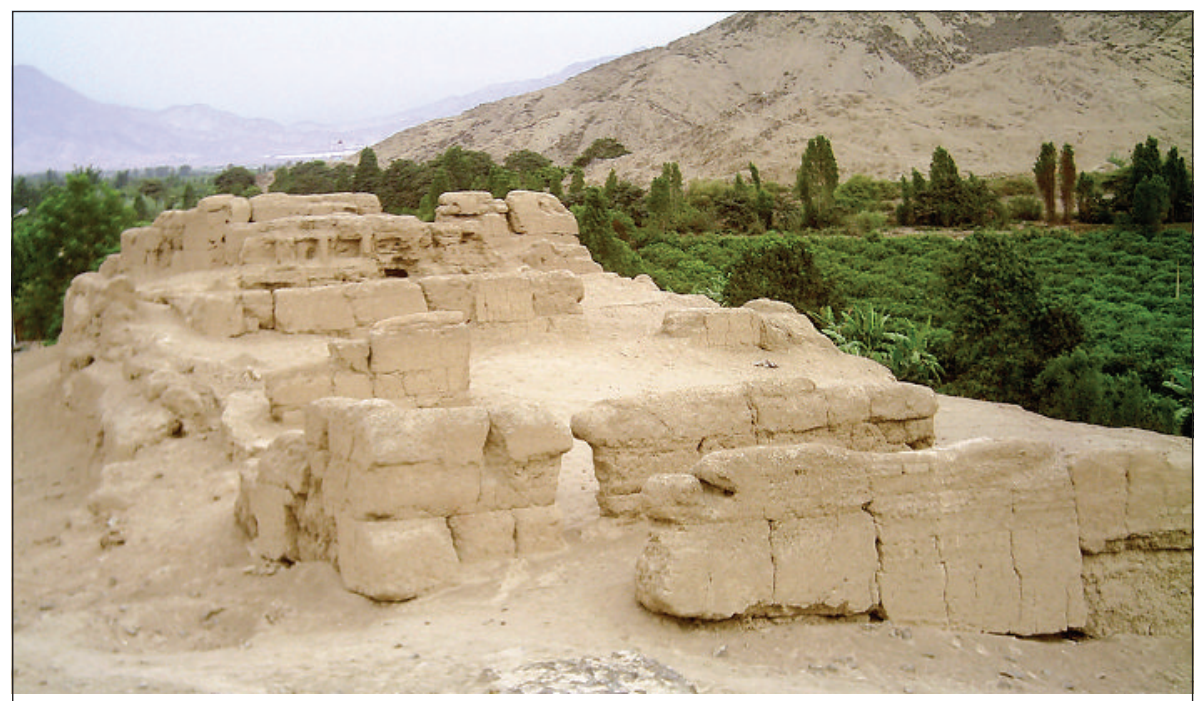

\section{EDIFICIO LA BANDURRIA}

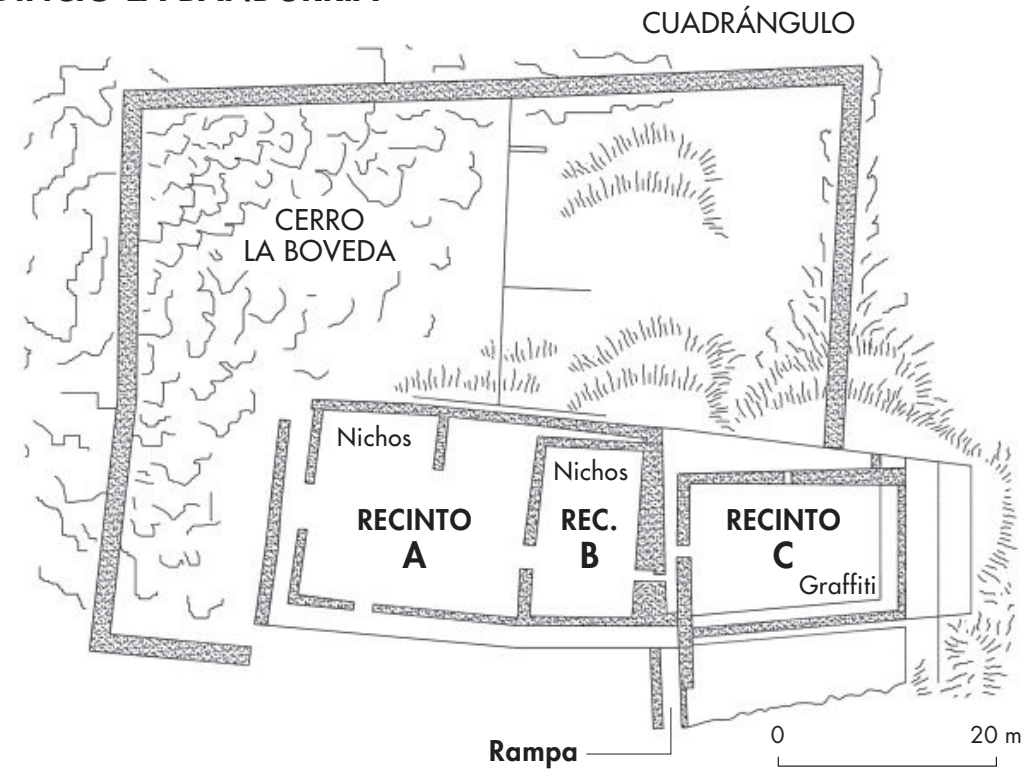

\section{GENERACIÓN Y PROPORCIONES}
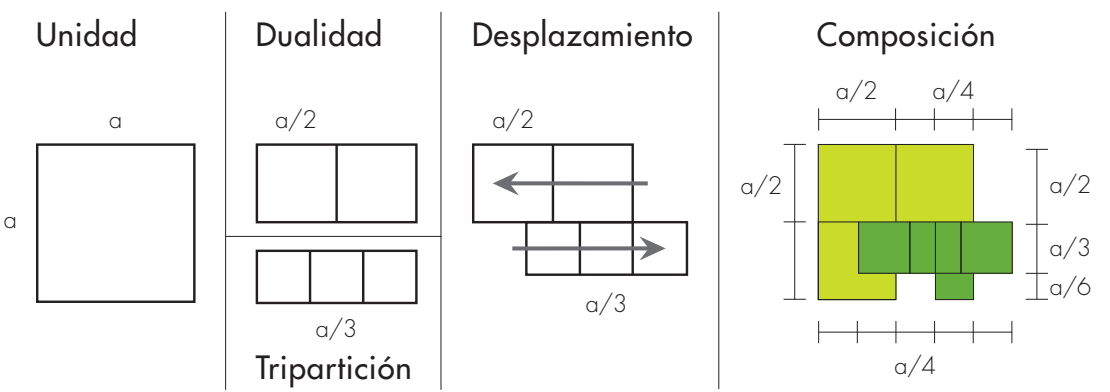

Figura 4. Edificio La Bandurria (Alvino \& Guzmán 2016: 146) y planta con propuesta de generación y proporciones del edificio mismo (elaboración propia). Figure 4. La Bandurria building (Alvino \& Guzmán 2016: 146) and floor with proposal of generation and proportions of the same building (own elaboration). 


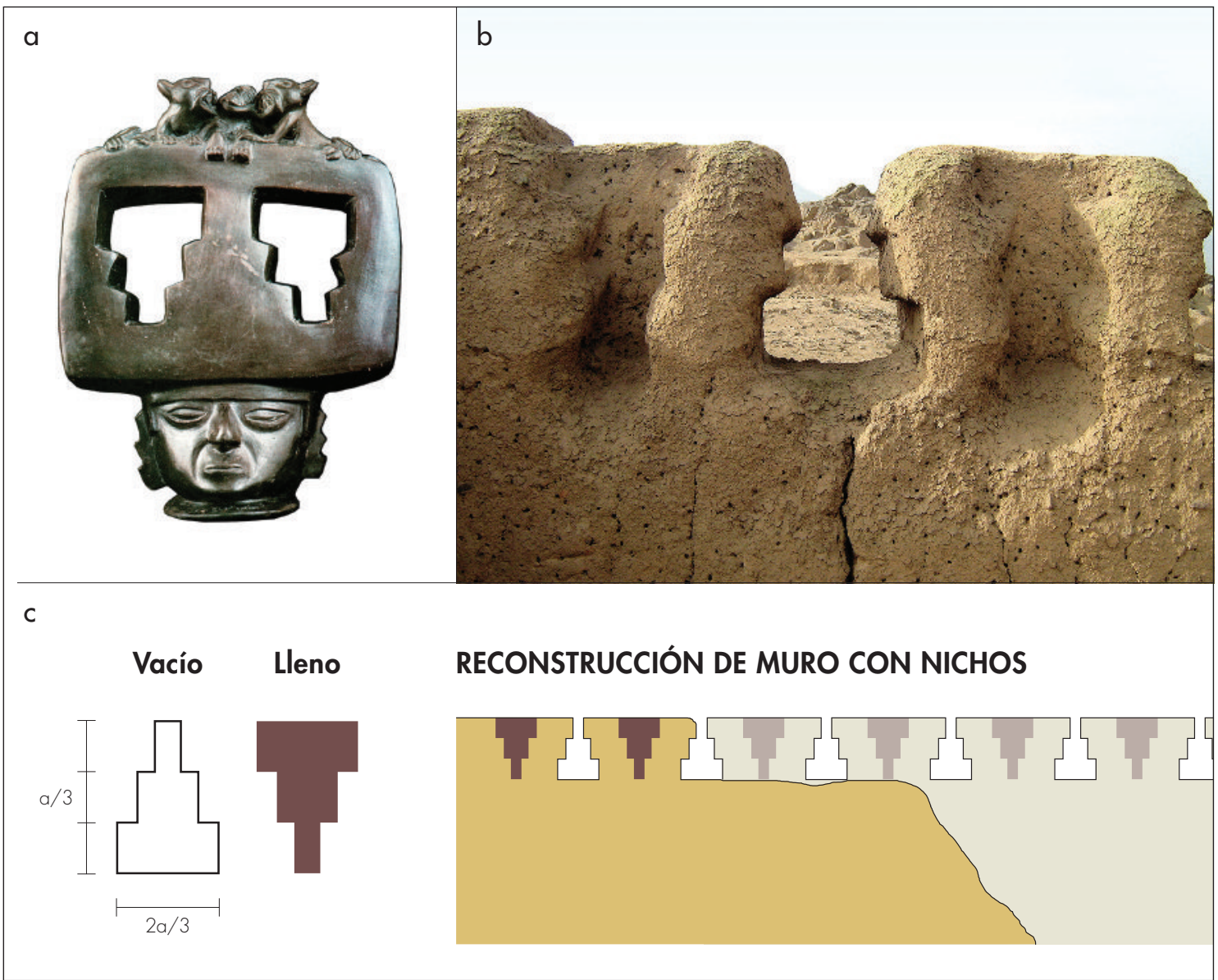

Figura 5: a) Vasija Chimú con cabeza y tocado arquitectónico (Lavalle \& Lang 1990); b) nichos escalonados de La Bandurria. (Fotografía: Jorge Alvino); c) proporciones y reconstrucción de muro con nichos escalonados (elaboración propia). Figure 5: a) Chimu vessel with architectural head and headdress (Lavalle \& Lang 1990); b) stepped niches in La Bandurria. (Photograph: Jorge Alvino); c) proportions and reconstitution of wall with stepped niches (own elaboration).

entre sí (dos metros de espesor en total), cuya solución se debe a la necesidad de poder tener en ese frente, que mira hacia el oeste, ciertos elementos espaciales. Allí se construyó una serie rítmica de dos tipos de nichos: seis de forma cuadrangular (aproximadamente $75 \times 25 \mathrm{~cm}$ de lado y $55 \mathrm{~cm}$ de profundidad) y otros cinco de forma rectangular vertical muy delgados $(15 \times 50 \mathrm{~cm}$ de lado, por $35 \mathrm{~cm}$ de profundidad) intercalados entre los otros, sumando un total de once nichos, aunque los del sur se encuentran en muy mal estado de conservación. Lo interesante es que esta secuencia está orientada hacia el oeste, es decir, hacia el ocaso o muerte simbólica del sol, sobre todo en la fecha de los equinoccios (eje esteoeste), lo que sugiere que tienen una correspondencia estética singular cuando el sol de la tarde alumbra con ciertas tonalidades doradas o naranja, recreando de manera especial la percepción del recinto, con un juego dinámico por la alternancia y las profundidades diferenciadas (Guzmán 2016: 124-131).

De lo revisado se observan ciertas lógicas recurrentes en el diseño de la organización espacial. Con todo, la arquitectura se sustenta materialmente se concreta o se hace posible mediante la construcción (proceso productivo social, lógica de sistemas estructurales y empleo de materiales), y ella implica el uso de principios organizativos: orientación, ejes, sectorización, trazo, partición y articulaciones, en concordancia con su inserción al paisaje y como parte de la recreación de la memoria social. 


\section{LA LÓGICA DE LOS MUROS}

La construcción intelectual de la experiencia del espacio es una abstracción a partir de la percepción de los diferentes elementos arquitectónicos que interactúan espacialmente de manera dinámica. Por sobre el sentido constructivo estructural de soporte, en sí mismo o de cargas actuantes, y el de definición física en cuanto límite funcional para el uso de determinados recintos, se debió tener claro el impacto visual de las superficies de los muros. Por un lado: dirección, sentidos, texturas, tectónica y la presencia de luces y sombras, y de otro, aquello aplicado con propósitos más específicos: lo pictórico y lo gráfico en sus diferentes variantes superficiales o volumétricas. Pero antes, hay que ponderar las diferentes jerarquías de muros, sea por su ubicación, por su magnitud o longitud, por su relación con el contexto en tanto alineamiento (orientación geográfica específica) o por su contenido explícito.

Los muros tienen una forma, una función y un propósito o finalidad. Aquí interesa resaltar las cualidades semánticas del muro, que se refieren a una lógica de la transmisión de significados a partir de la experiencia perceptual, el impacto que genera como envolvente y la seducción que puede ejercer como sistema de imágenes. Los muros son elementos que dirigen, definen sentidos del recorrido -del tránsito ritual- y concretan en conjunto recintos para usos diversos y complejos que implican cierta permanencia de participación grupal. En este sentido son escenarios que concentran la mirada e interactúan como medios de algún tipo de comunicación.

\section{Sobre los elementos tipológicos}

Se propone que las formas arquitectónicas estéticas chancay asociadas a los muros pueden clasificarse en:

1) Grafitis: incisiones o trazos sobre la superficie que transmiten cierta espontaneidad. Podrían considerarse, además de los pequeños bajorrelieves monocromos, las representaciones pictóricas o dibujos pintados (con algún tipo de "pincel").

2) Relieves: tratamientos murarios que destacan por su carácter tridimensional, sea "alto" (hacia afuera del nivel de la superficie) o "bajo" (hacia adentro). Cuando estos relieves se ubican en la parte alta a manera de secuencia, muchos los denominan "frisos". En algunos casos, la constitución de la materia con la que se expresa el ícono es de mayores dimensiones, lo que genera que se perciba como una entidad volumétrica propia adosada al muro, definida por algunos como "bulto".

3) Voladizos: son proyecciones de superficie horizontal del mismo muro, realizadas por el incremento en dimensión de su espesor, de tal manera que la unidad constructiva con su respectivo acabado se adelanta y cubre en voladizo un área determinada, generalmente en la parte superior del muro. (Se les llama "cornisas", aunque tomado de un contexto occidental).

4) Vanos y nichos: si bien son diferentes, pueden asociarse por el nivel de profundidad o tridimensionalidad que presentan. El vano es el espacio vacío dentro del muro, que permite la relación (visual o de tránsito) entre dos espacios diferentes o separados, mientras que el nicho es cualquier concavidad dentro del espesor del muro, sin atravesarlo, es decir, tiene un fondo.

5) Remates y "almenas": son las formas particulares en que la cabecera de los muros adopta algún tipo de diseño, generalmente de manera escalonada, o en secuencia entre tramos altos y bajos.

6) Enlucidos: son las capas de arcilla que le otorgan homogeneidad a la superficie del muro (pared) y sobre ellas se aplican diferentes capas de pintura, de tal manera que los recintos o el edificio en su conjunto presenta una cromática particular.

7) Pinturas murales: son representaciones trazadas sobre la superficie muraria con pigmentos, tintes o pinturas, y que representan formas, motivos, diseños o escenas. Se utilizan pinceles, son formas realistas o abstractas y responden a contenidos culturales profundos.

\section{Sobre las expresiones "decorativas" arquitectónicas.}

A partir de la clasificación anterior, generada por el reconocimiento empírico, a continuación se desarrollan algunos casos específicos en los que se muestra la expresividad y el manejo estético chancay.

\section{Los grafitis de La Bandurria y Macatón}

En La Bandurria, hacia la esquina sureste del edificio se ubica un pasaje que rodea la plataforma superior. Inmediata hacia el arranque de la pared este, existen aún algunos grafitis sobre la superficie alisada. Se trata de tres pequeñas formas figurativas ordenadas de manera vertical y sucesiva, todas fueron elaboradas de manera 


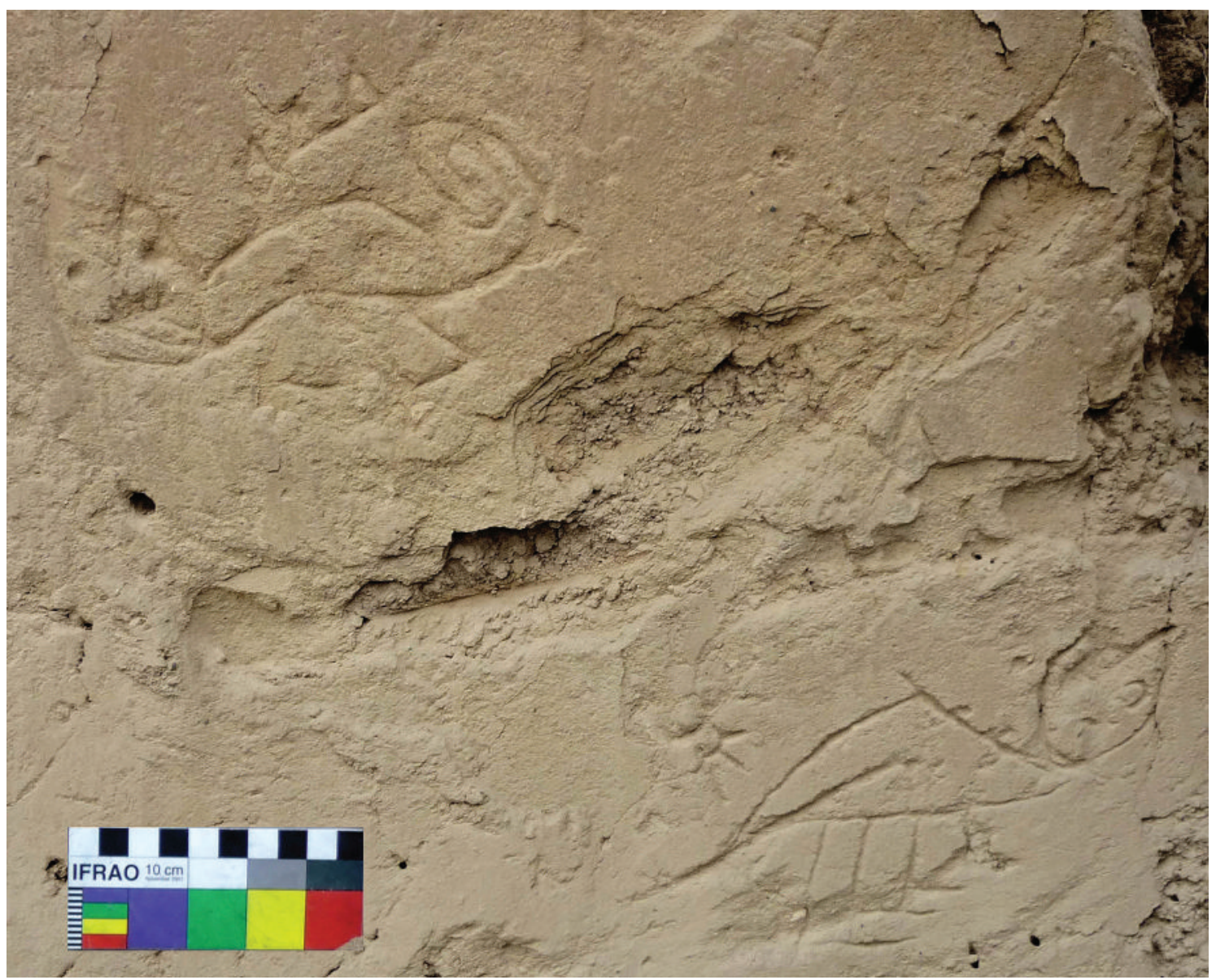

Figura 6. Grafiti de La Bandurria. (Fotografía: Jorge Alvino). Figure 6. Grafiti in La Bandurria. (Photograph: Jorge Alvino).

rápida y precisa por medio de un punzón o buril. Las imágenes, si bien parecen ser naturalistas de manera general, lo son en sus rasgos o partes, que se combinan produciendo finalmente una imagen icónica compuesta, quizás a partir de tres figuras reconocibles, existiendo en todos los casos el perfil de un felino (fig. 6).

Grafiti A. Compuesto de tres formas sintéticas reconocibles: cabeza triangular con dos triángulos que la coronan con dos puntos en la parte inferior de los mismos. Un pequeño desprendimiento parece coincidir con lo que pudo ser una boca con dientes. Una continuidad formal podría corresponder a un cuerpo figurativo de forma semicurva, del cual se desprende hacia su parte inferior unas líneas a modo de extremidades inferiores. Hacia la parte superior, una línea sinuosa se asocia a tres pequeños triángulos sucesivos, mientras que el remate de la figura es una espiral de dos giros hacia su interior, y el sentido de la figura parece conducir a la misma, de izquierda a derecha.

Grafiti B. Muy destruido en épocas recientes, la única parte que aún existe parece corresponder a una extremidad inferior a modo de garra.

Grafiti C. De figura similar al primero, la cabeza evidencia forma más hexagonal y presenta los ojos en círculo y la boca apenas insinuada. El cuerpo es casi un triángulo con el ángulo mayor hacia arriba (o cúspide del lomo). En este caso, de la parte inferior del cuerpo se desprenden cuatro líneas quebradas paralelas y en orden de tamaño, las que parecen representar extremidades inferiores. El sentido de esta figura, al contrario de la del grafiti A, parece ir de derecha a izquierda. 


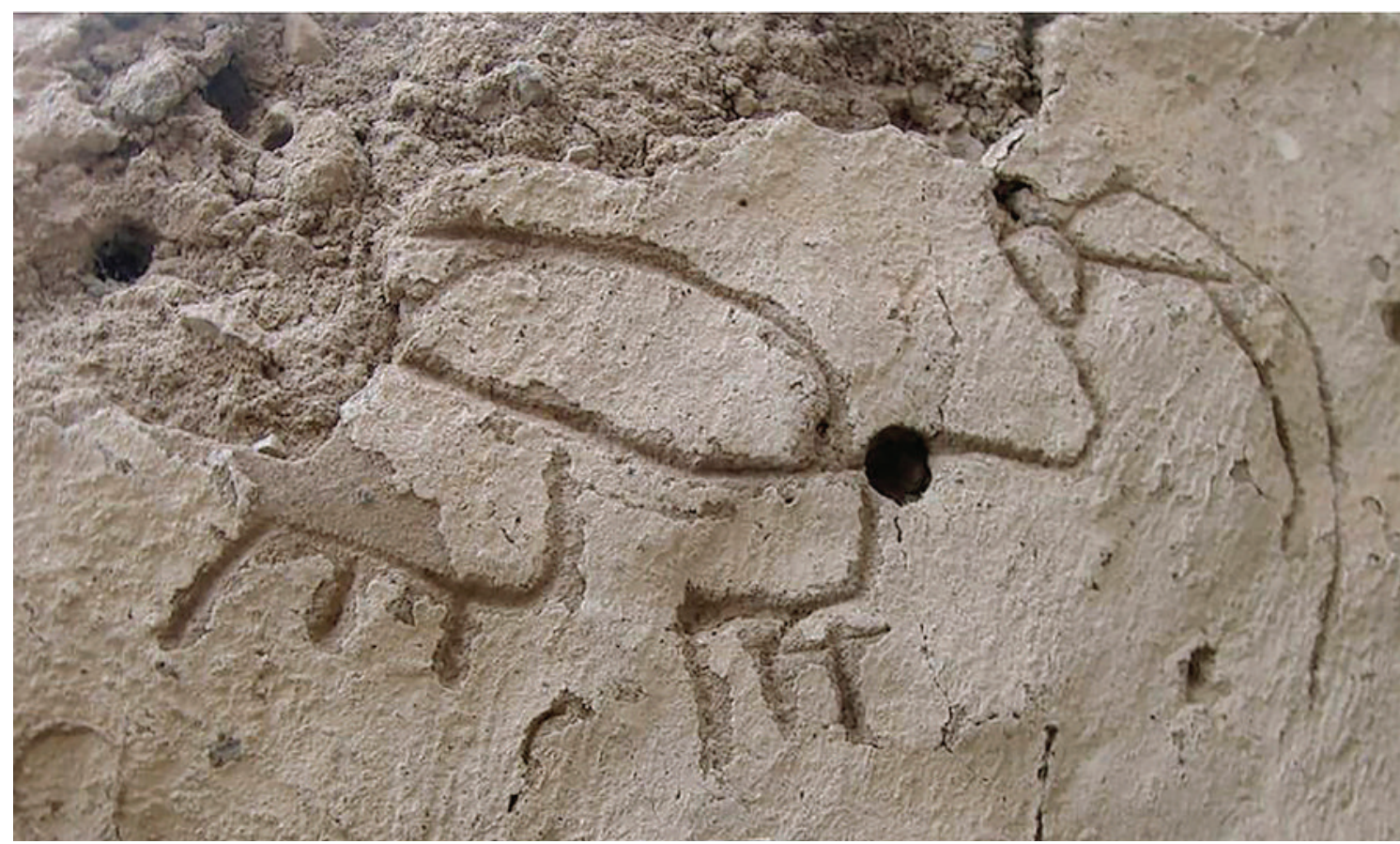

Figura 7. Grafiti de Macatón. (Fotografía: Carlos Hidalgo). Figure 7. Grafiti in Macatón. (Photograph: Carlos Hidalgo).

En un trabajo anterior (Alvino \& Guzmán 2016) se discutió sobre las posibles funciones de lo señalado, las que serían parte inherente de la función del edificio mismo (es probable que existan muchas más sin descubrir), respondiendo a consideraciones de emplazamiento, técnica constructiva y singularidad en el valle, como del período chancay-inca.

En el caso de Macatón, entre los restos de grandes recintos de tapias enlucidas de blanco, hemos registrado hace ya varios años evidencias de grafitis, entre los cuales destaca uno, posiblemente el perfil de un ave marina de largo pico (quizás un pelícano), pero también podría interpretarse como un felino muy sintetizado si la lectura formal fuera de izquierda a derecha (aclarando que al grafiti le falta un fragmento trabajado y que correspondería a la cabeza del felino). Muy cerca, en la parte inferior existe una figura humana estilizada (fig. 7). Otro grafiti (fig. 8) trazado sobre un enlucido crema representa la figura fragmentada de la parte inferior de un personaje visto de frente. En este caso deducimos que se trata de un personaje antropomorfo visto de frente, pues presenta piernas estilizadas (dos líneas gruesas verticales), pies humanos con cinco apéndices que serían los dedos y con el talón hacia el interior; además un área trapezoidal superpuesta con entramado interior hace recordar un textil tipo reticulado o ajedrezado; finalmente la poca superficie superior que correspondería al torso se encuentra cubierta con chevrones alineados verticalmente e invertidos (se conservan tres de posiblemente cinco), muy similares a escamas. Muy cerca, a su derecha, existe otro grafiti que representa un rectángulo, posiblemente un edificio. Hay que agregar que los grafitis de Macatón se han vinculado a otras manifestaciones chancay: "están relacionados con las representaciones de diseños antropomorfos, zoomorfos y geométricos de las telas pintadas Chancay" (Tarazona 2000: 38).

Entender la dimensión cultural de los grafitis es complejo; una definición es la que expone Kampen al considerarlas como "representaciones esgrafiadas y pintadas sobre los edificios (especialmente en paredes y pisos) que son una manifestación del arte popular distinta de la pintura, el dibujo o la escritura formal" (Kampen 1978: 158). Se plantea entonces una definición al margen de lo institucional y que no involucra el proyecto concertado del edificio, lo que dejaría al grafiti como un acto casi de iniciativa personal y hasta cierto punto furtivo. Esto es siempre difícil de sostener, 


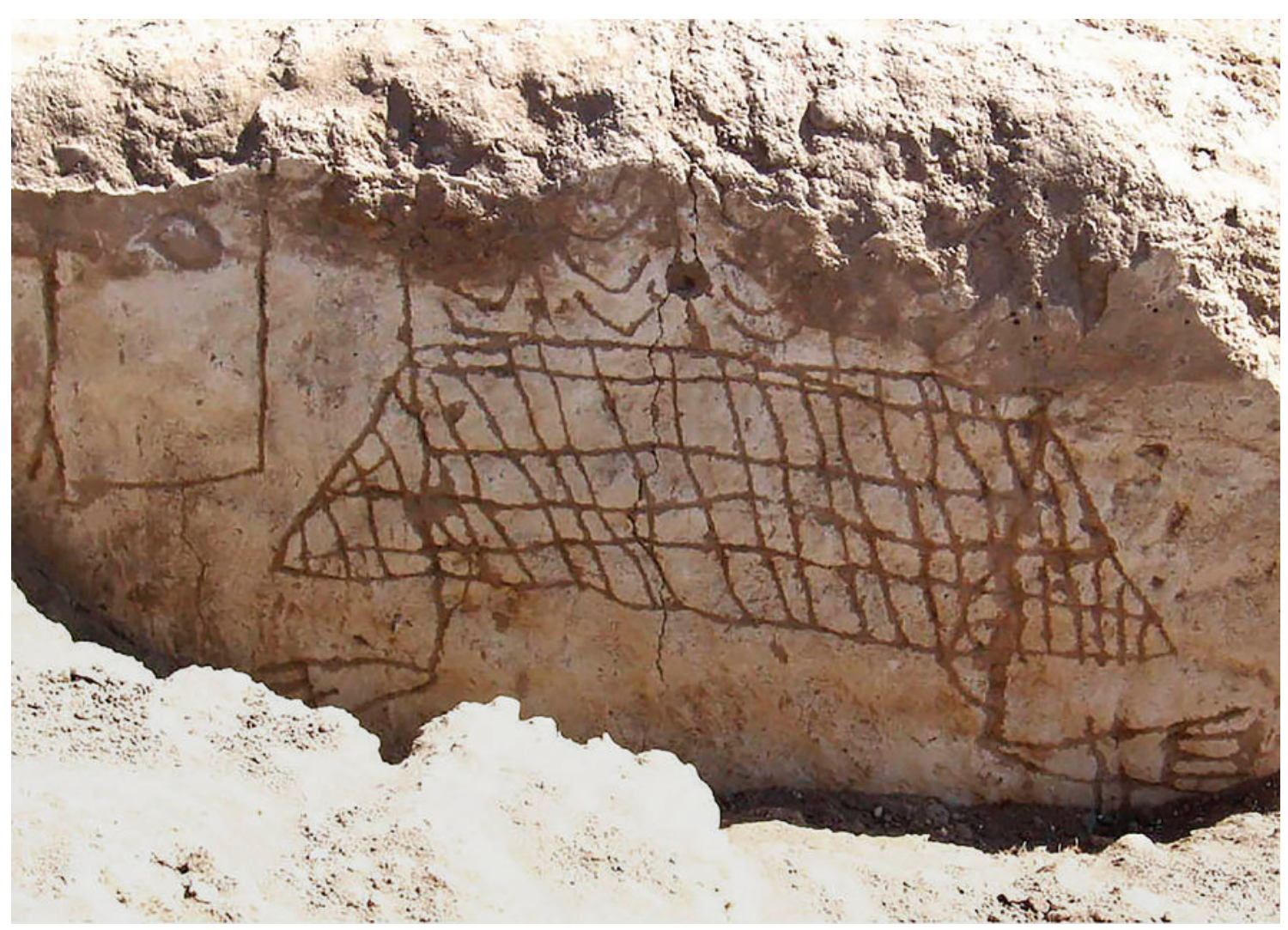

Figura 8. Grafiti de Macatón. (Fotografía: Carlos Hidalgo). Figure 8. Grafiti in Macatón. (Photograph: Carlos Hidalgo).

más aún cuando al haber sobrevivido a su realización se evidencia su aceptación e inclusión en la obra final.

En el área andina los grafitis han sido registrados en lugares de clima seco, como los de la franja costera $\mathrm{y}$, además, en distintos períodos arqueológicos. Por ejemplo, existen por ejemplo en Chankillo, en el valle de Casma (Reiche \& Fung 1956, asociados a un edificio del Período Inicial (1200 AC-200 AC); al sur, en el gran sitio Nazca de Cahuachi, representando antaras (Silverman 1987: 12); también son conocidos los grafitis en Moche, durante el Intermedio Temprano (200 AC-550 DC), en donde aparecen personajes humanos o divinizados, por ejemplo en Huaca El Brujo (Franco, Gálvez \& Vásquez 2001: 364) o el que existía en Pañamarca, valle de Nepeña (Bonavía 1974: 59); también en Mateo Salado en el valle del Rímac (Espinoza 2014: 103) e inclusive en Pachacamac, en el edificio con rampa 2 existen grafitis de forma muy sintetizada (Franco 1993), o representando peces (Praet et al. 2017: 16). Estas diversas evidencias indican que su presencia en contextos importantes debió corresponder a un tipo de conducta que se mantuvo vigente a lo largo de los siglos, y que aún no ha sido estudiada sistemáticamente.

\section{Los relieves de Hualmay y Laure}

Existen pocas referencias con respecto a relieves como forma de decoración en los edificios chancay. En Hualmay, en la margen izquierda y cerca de la desembocadura del río Huaura, al norte de la ciudad del mismo nombre, existe un gran sitio arqueológico que posee grandes edificios de adobe y tapial, emplazados frente al mar. Según Arturo Ruiz, en uno de estos edificios existían decoraciones de "figuras estilizadas de aves, peces y circunferencias" (Ruiz 1982). A partir de un croquis se ha reconstruido la apariencia de esta escena, que se puede identificar como marítima y podría estar asociada a otras existentes en edificios con rampa, como en Chan Chan o Huaca La Palma en Maranga (fig. 9). 


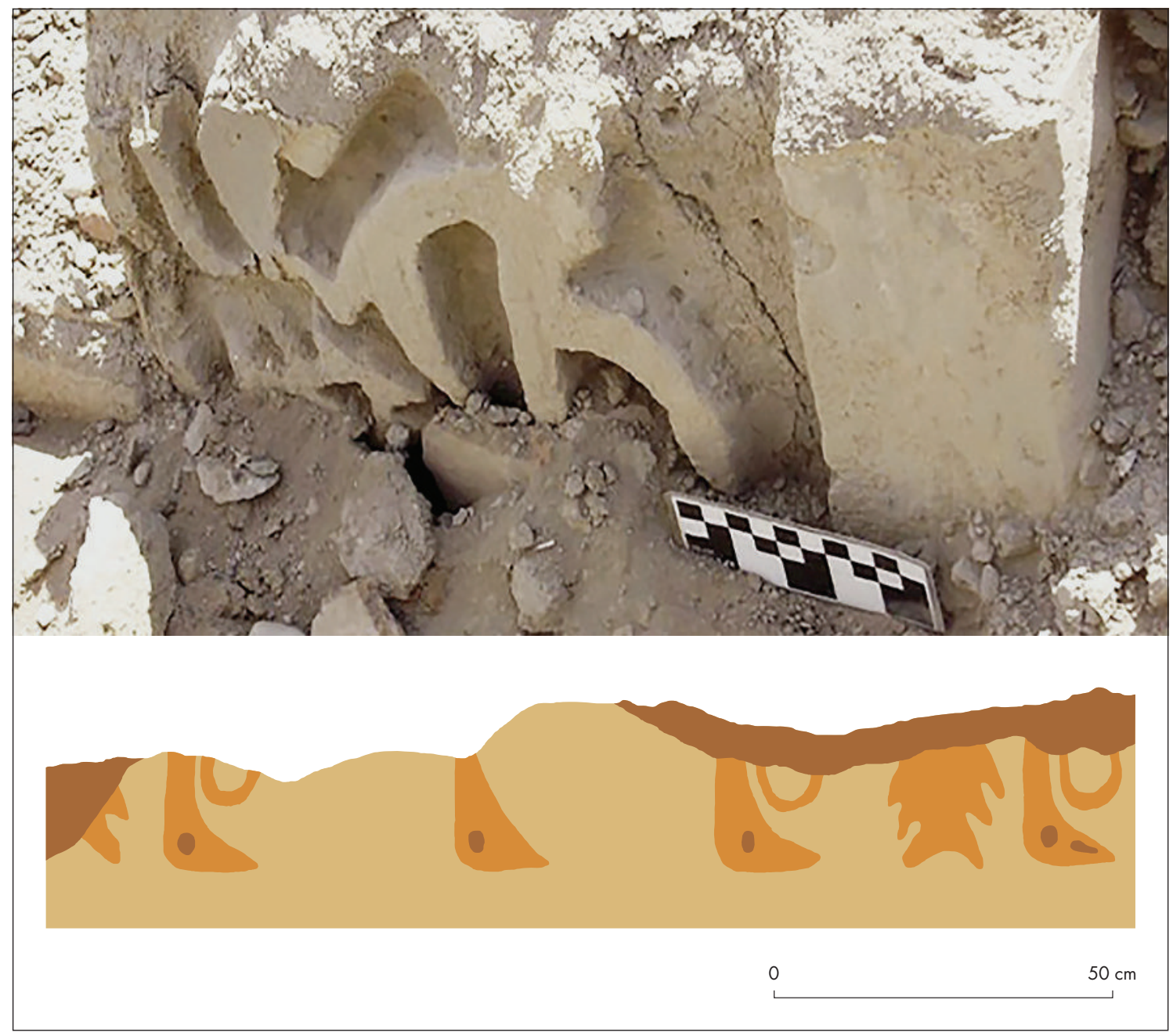

Figura 9. Relieve expuesto en Hualmay (Fotografía: Jorge Rodríguez) y reconstrucción de un muro con relieves de aves en secuencia, hoy desaparecido (elaboración propia a partir de croquis de Ruiz 1982). Figure 9. Exposed relief in Hualmay (Photograph: Jorge Rodríguez) and reconstitution of a wall with birds' reliefs in sequence (which has now disappeared) (own elaboration based on sketches by Ruiz 1982).

Hay al menos cuatro figuras zoomorfas fragmentadas de las cuales se conserva la parte inferior. Representan de manera muy estilizada la cabeza y el cuello de un ave con pico girado hacia la derecha del espectador. La comisura del pico y el ojo izquierdo se aprecian claramente a modo de bajorrelieve. Las cuatro imágenes se hallan distanciadas cada $40 \mathrm{~cm}$ de su respectivo eje vertical. Otra imagen es la de un pez, cuyo perfil oval engrosado y aserrado representando sus respectivas aletas, es muy característico en pinturas murales en Pachacamac en el valle de Lurín, así como en Huadca en el valle del Rímac (Bonavía 1974: 122 y 127).
Otro ejemplo interesante proviene del Museo Arqueológico de Huaral (fig. 10). Se trara de una pieza procedente de Laure (sitio arqueológico en el valle bajo de Chancay y emplazado muy cercano al mar), hecha de arcilla para adobes y que ha sido trabajada en bajorrelieve en tres de sus cuatro lados verticales con representaciones figurativas de aves marinas, tramas geométricas (a modo de redes de pesca), y remates escalonados (como los descritos más adelante para Tronconal). Todos estos elementos se encuentran ordenados de manera que parecieran componer una forma arquitectónica decorada. Un cuarto lado vertical muestra haber sufrido roturas, 


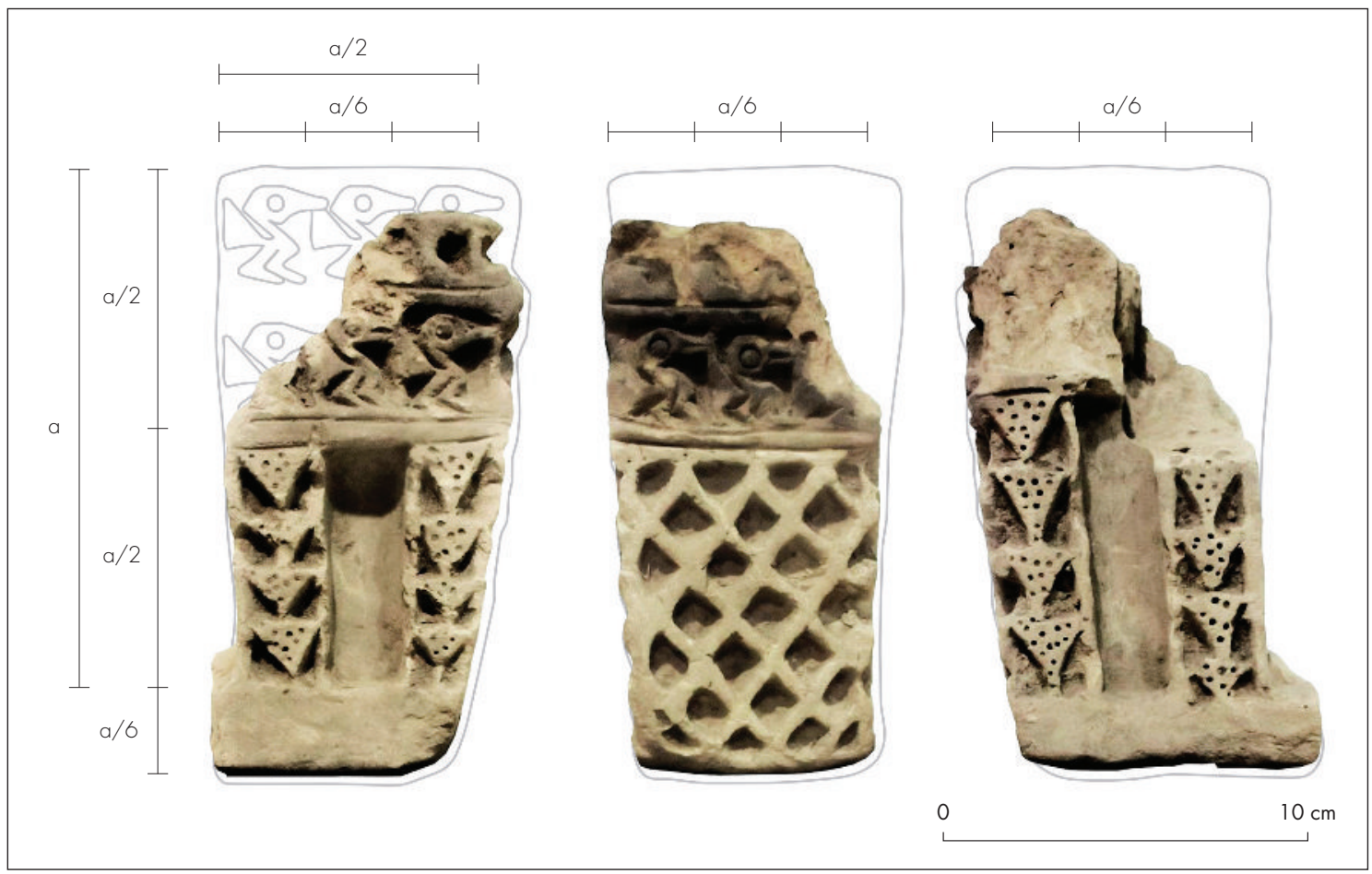

Figura 10. Relieve de arcilla proveniente de Laure, valle de Chancay (Museo Arqueológico de Huaral 2017). Figure 10. Clay relief from Laure, Chancay valley (Huaral Archaeological Museum 2017).

por lo que se deduce que pertenecía a una escena mayor a la que se articulaba con un espacio vacío o vano. A pesar de lo fragmentado de este ejemplar se pueden reconstruir algunos principios de proporción y orden en su tratamiento formal. Si bien no son modelos a escala, mantienen algunos principios de proporción que existen en los edificios chancay. Algunas de estas relaciones son: 1:2 en la configuración general, 1:3 en división general, y 1:6 en detalles y subdivisiones internas.

\section{Los voladizos de Pisquillo Chico, Pancha la Huaca y Guarabí}

Algunas veces, los voladizos son solo de una proyección, generalmente cuando antecede o se encuentra debajo de un nicho; otras veces se encuentran de manera sucesiva hasta en dos o tres proyecciones. La luz que cubre cada volado -entre $5 \mathrm{a} 10 \mathrm{~cm}$ - se sustenta estructuralmente en el desplazamiento de las unidades constructivas (adobes) hacia el exterior del aplomo del muro. En el sector noreste de Pisquillo Chico, de carácter residencial administrativo y de jerarquía espacial justamente por estos detalles, se conservan algunos volados simples y otros sucesivos (fig. 11). En el primer caso se desarrollan a media altura del muro, en la parte inferior de vanos cúbicos alineados. En el segundo caso se presentan en la parte interior de recintos de aparente uso residencial.

En Pancha La Huaca se registraron dos sectores con presencia de voladizos, algunos hasta triples $(\mathrm{Ne}-$ gro 1991: 62), con revoque fino (fig. 11). Los volados simples (uno solo) se ubicaban en la parte exterior de los edificios con banquetas bajas y, los volados dobles, rodeando el perímetro de edificios o al interior de recintos con nichos cúbicos, situación que remarcaría su importancia.

Otro tipo de volados se encuentran en la margen derecha del valle bajo del río Chillón, en donde existen asentamientos vinculados a la sociedad chancay, aunque sin la debida investigación arqueológica. Ellos son Macas, Trapiche y Guarabí, todos emplazados en las laderas bajas de los cerros a partir de una adaptación escalonada. Allí, entre las edificaciones de tapia, aparecen voladizos en la parte superior de los altos muros, en este caso simples y casi exclusivamente hacia el interior de los recintos. 

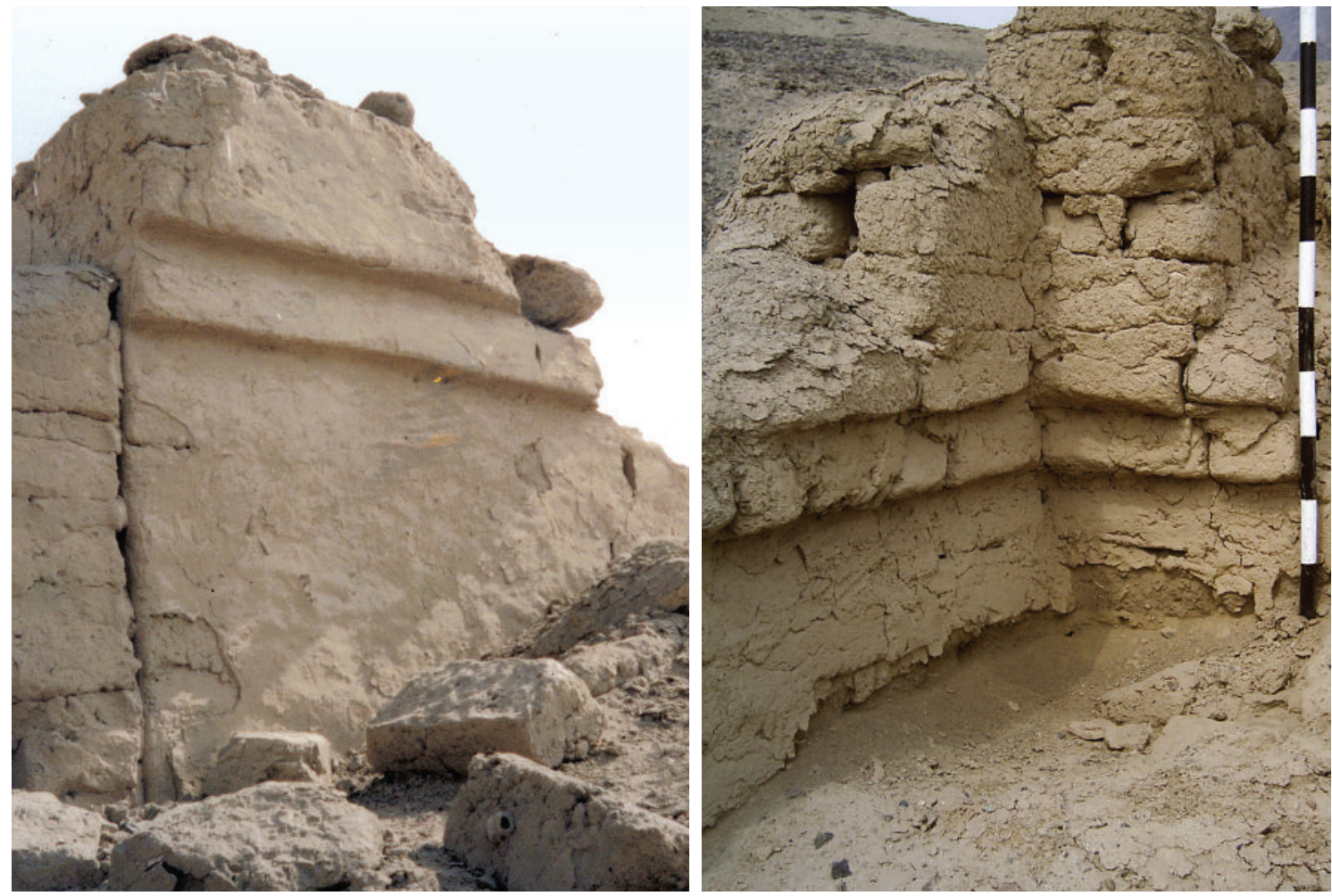

Figura 11. Voladizos dobles en Pisquillo Chico y Pancha La Huaca. (Fotografía: Jorge Alvino). Figure 11. Double corbels in Pisquillo Chico and Pancha La Huaca. (Photograph: Jorge Alvino).

\section{Vanos y nichos}

Se trata de pequeños espacios, generalmente de forma cúbica, que se insertan en los muros a modo de nichos elevados. Son de los pocos elementos que se repiten constantemente en edificios de carácter residencial. Los más grandes, construidos en adobe, se encuentran en los sitios de Pisquillo Chico, Pancha La Huaca y Portillo (fig. 12). Otros nichos son menores y se realizaron en diferentes sistemas constructivos.

Durante mucho tiempo se ha especulado con la presencia de estos elementos en los edificios de la costa andina, su mención es casi inexistente en las crónicas tempranas y pocas veces se han encontrado en contextos intactos. En Chan Chán se han hallado nichos de forma cúbica, pero de mayores dimensiones, con evidencias de presencia de objetos. En el interior de algunos de "estos cubículos habían restos de troncos hincados en el centro, dificultando así las posibilidades de contener a manera de depósito... en una de estas "hornacinas" el tronco o poste central tenía labrada una especie de rostro humano en el extremo superior" (Campana 2006: 288). En el año 2009 se descubrieron en el mismo Chan Chan 17 ídolos de madera al interior de unos nichos, aunque estos son bajos y más verticales. A pesar de estas referencias y que en los museos existen ídolos chancay de madera, no se puede aseverar aún si los nichos servían de contenedores de este tipo de objetos. Lo que sí es evidente es que se presentan agrupados en fila y siempre en recintos internos de edificios sin plataforma y con carácter más bien residencial.

\section{Almenas}

Las almenas son remates formales ubicados en la parte superior de los muros, de tal manera que el perfil se torna dentado o escalonado. Existen pocas referencias respecto de este rasgo, el cual ha sido registrado en asentamientos tardíos asociados a la presencia Tawantinsuyu en valles de la costa. Se pueden mencionar Ungará en Cañete, Uquira en Asia y La Vuelta en Mala. 

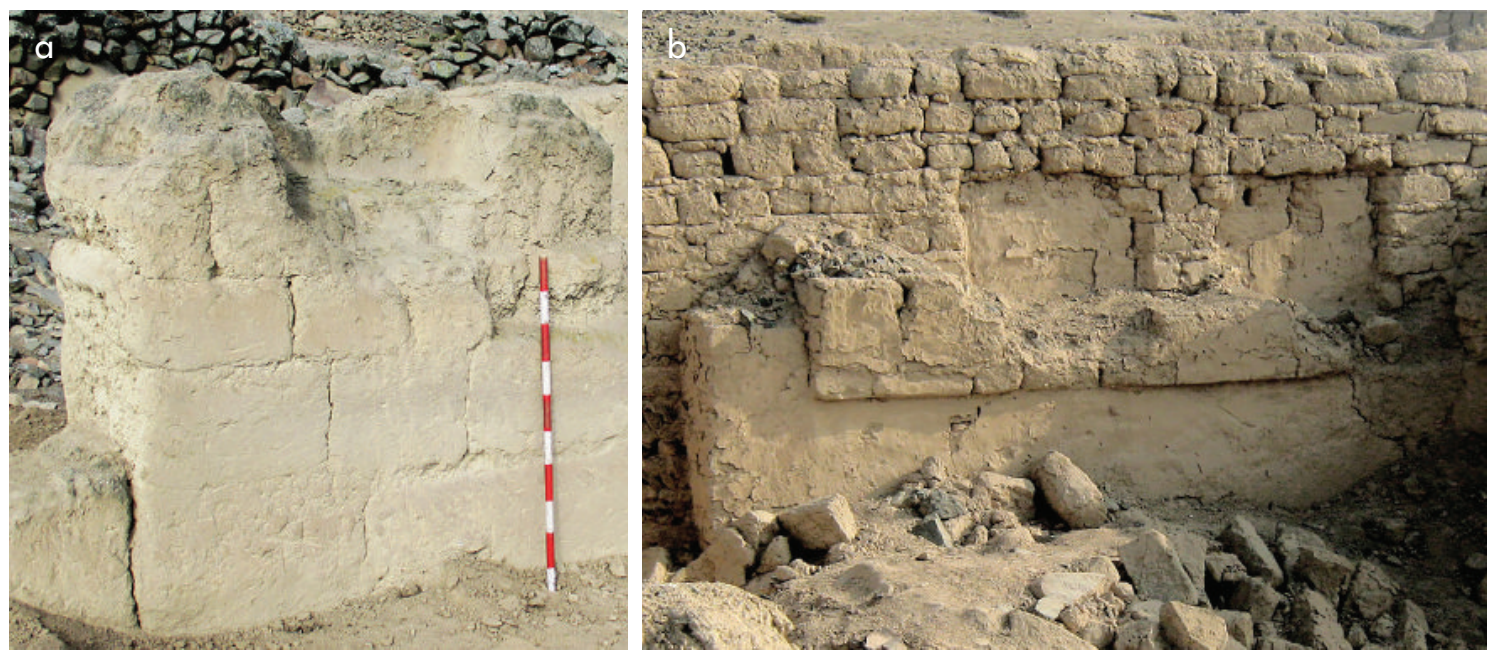

Figura 12: a) nicho en Portillo, sector residencial alto; b) doble nicho en Pisquillo Chico. (Fotografía: Jorge Alvino). Figure 12: a) niche in Portillo, high residential sector; $\boldsymbol{b}$ ) double niche in Pisquillo Chico. (Photograph: Jorge Alvino).

En Chancay, el inventario del valle efectuado por Santiago Agurto (1974) lo tiene registrado para el sitio de Tronconal:

Un hecho interesante es que uno de los edificios que están en mejor estado, tiene una especie de almenas, en las cuales se representa el signo escalonado, o sea un escalón en doble grada. Existen 2 o 3 de estas almenas muy destruidas, ocupando únicamente la mitad de un muro sobre el cual se asientan. Tienen 40-50 $\mathrm{cm}$ de ancho y están asentadas sobre un muro de 1-1,2 mts (Agurto \& Sandoval 1974. Ficha 23I n $14 \mathrm{~K} 01 \mathrm{~s} / \mathrm{n})$.

Si bien este rasgo ya no existe, por las descripciones que proporciona la ficha respectiva se sabe que se encontraba en el muro testero del edificio con rampa 1 de este asentamiento, el cual además presenta remodelaciones durante el Horizonte Tardío, pues al ser edificado en adobes, fue revestido de un revoque que tiene un tratamiento similar a los paños de tapial.

\section{Enlucidos}

A partir de reconocimientos superficiales se ha verificado que, generalmente, se enlucían algunos edificios principales, como los edificios con rampa central, en donde se ha registrado pintura amarilla (5Y8/6) en sus paredes internas. También, se ha detectado el uso de pintura blanca en muros de tapial de Macatón y en algunos muros de adobe en Laure. En todos los casos los pigmentos son muy leves y han desaparecido por haber estado expuestos al sol. Sin embargo, se puede sugerir que en algunos muros semienterrados subsiste aún en perfecto estado. No se han registrado pinturas murales o escenas pintadas.

Por referencias históricas se sabe incluso que la ciudad de Chancay fue fundada por el virrey Conde de Nieva en 1562 con el nombre de Villa de Arnedo en el lugar denominado Tambo Blanco (Romero 1935: 382). Este fue posiblemente un sitio chancay vigente durante el Horizonte Tardío y cercano al gran Camino de los Llanos o Capaq Ñan de la costa. Este lugar no ha sido aún identificado hasta hoy, pero resulta sugerente el adjetivo cromático añadido a su denominación.

\section{Pinturas murales}

Finalmente existen pinturas murales que exponen imágenes a partir del contraste bidimensional, policromo o valorado. La pintura mural exige un tratamiento superficial que sustente su conservación y elaboración. Se trata de un proceso casi siempre delicado, motivo por el cual pocas veces las pinturas se conservan intactas.

En Hualmay se encuentra expuesta una pintura mural monocroma sobre un muro de enlucido blanco, aparentemente el más usado en el sitio. La pintura se compone de una hilera de formas geométricas que repite la asociación de dos figuras: un escalonado ascendente de izquierda a derecha y una greca que se desarrolla ortogonalmente hacia el interior en sentido horario. 


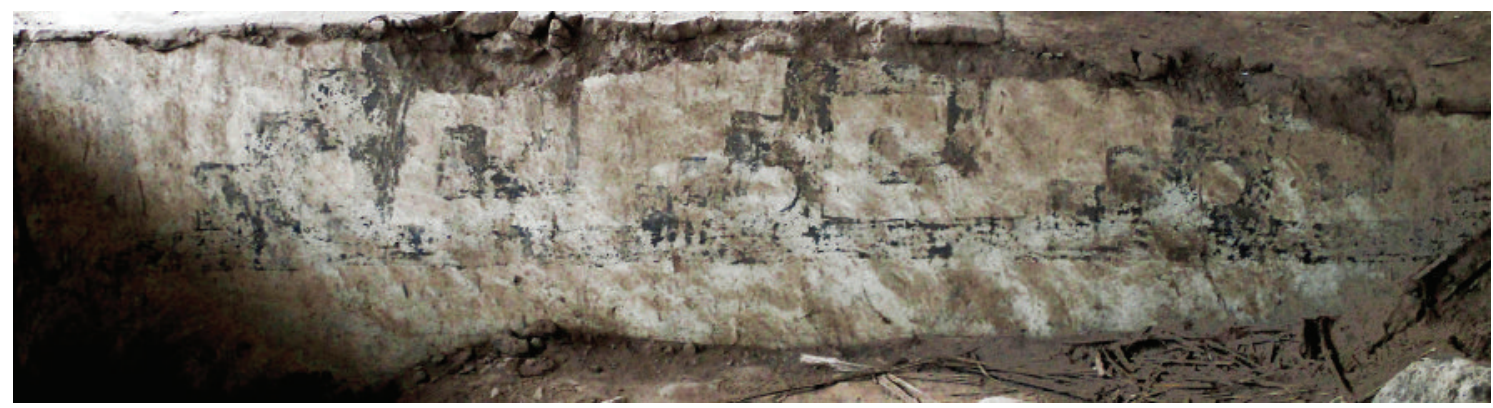

Figura 13. Pintura mural expuesta en Hualmay. Figuras geométricas en serie. Figure 13. Mural painting exhibited in Hualmay. Serial geometrical figures.

Ambas figuras son del mismo ancho, se yuxtaponen lateralmente y consolidan una nueva figura compleja en cuyo centro aparece un círculo vacío. Esta figura compleja se repite en el mural hasta cuatro veces siguiendo un sentido de izquierda a derecha y usando como forma conductora una banda horizontal inferior. Toda la serie se encuentra pintada de negro, por lo que contrasta directamente sobre el fondo blanco (fig. 13). No nos extenderemos en el análisis de esta pintura, pero hay que resaltar que es un diseño casi arquetípico y que aparece en distintos edificios de la Costa Central andina, como los ubicados en Chan Chan, Pachacamac, Pampa de Flores, etc. Además, hay que recordar su presencia en la decoración de cerámicas y textiles.

\section{LAS REPRESENTACIONES DE LA ARQUITECTURA}

Existen representaciones de edificios en diversos materiales, principalmente cerámica y textiles. En el caso de las primeras, estas no parecen haber tenido una función utilitaria doméstica (como de recipiente, por ejemplo), antes bien, se trata de formas volumétricas complejas y expresivas realizadas con técnicas propias y decoración estilística. Tienen la capacidad de representar formas edificatorias tridimensionales, generalmente en interacción espacial y temporal humana (figuras humanas ubicadas utilizando los espacios) y pudieron tener muchos usos: expresivas educativas, ofrendas, maquetas de diseño de edificios, etc. Dichos usos no han sido probados debido a la falta de contextualización de los hallazgos y su explicación es por ello incompleta.

Estos objetos son "maquetas", es decir representaciones -anteriores o posteriores a una posible materiali- zación- ${ }^{10}$ de una obra edificatoria y su función podría ser múltiple. Por ejemplo, se ha documentado su presencia en entierros mochica (Castillo et al. 1997), por lo que su sentido social como vinculante entre un personaje y un edificio podría cobrar algún significado trascendente. Sin embargo, la interpretación de estas "maquetas" posee varias limitaciones como, por ejemplo, la dificultad de hallar los edificios representados, construidos y aún conservados. Otra limitación, desde el punto de vista técnico, es su dificultad de representar a escala una posible proyección del edificio, lo cual es más difícil de probar.

Aun así, se postula que este objeto (a escala o no) podría representar parcialmente el significado social del edificio. La posibilidad de que sea un "diseño" previo no puede probarse a menos que se encuentre cronológicamente una "maqueta" anterior a un edificio representado y asociado estratigráficamente a este, ${ }^{11}$ sin embargo, tampoco se puede dejar de considerar que, al menos los mayores edificios públicos, fenómenos permanentes y onerosos, se realizaran de manera espontánea y bajo la dirección empírica de un constructor. Al igual que la alfarería y la textilería, la arquitectura andina no era solo construcción e imitación de lo real, y evidentemente podía reconocer la realidad y deconstruirla para proyectar finalmente formas nuevas. Si este fuera el caso, la "maqueta" se transformaría en "modelo", es decir, una estructura concebida para ser realizada o conservada en la memoria materializada, con todas las posibilidades de ser trasladada, copiada y valorada por la sociedad.

Para el caso Chancay, es importante analizar una pieza de cerámica publicada por Wolfgang Wurster (1982), ${ }^{12}$ quien la llama "modelo arquitectónico". Según el investigador estaría representando "un caserío, con varias casas con techos inclinados, y un sistema de patios y pasadizos amurallados. [...] Dentro del recinto prin- 
cipal está sentada una figura humana" (Wurster 1982: 261). El análisis en planta de esta "maqueta" presenta innegables similitudes con la estructura formal de los conjuntos edificatorios que poseen rampa central que, como se señaló, están conformados por tres unidades arquitectónicas de características similares entre sí (Guzmán 2016: 203-243). Además, este "modelo arquitectónico" es directamente asociable al conjunto tripartito A2 (rampas cruzadas perpendiculares) existente en Pisquillo Chico (Alvino 2013: 175). Los ejemplos utilizados por Wurster no reconocían aún este aspecto: "La variedad del arreglo de los edificios, la complejidad de los patios abiertos y sus relaciones mutuas muestran en este modelo cualidades volumétricas y espaciales de la arquitectura chancay, de las que no quedan huellas suficientes en las ruinas mismas" (Wurster 1982: 261).

Se podría considerar que el modelo detallado representaría el conjunto tripartito de edificio con rampa central que se ha descrito anteriormente en Pisquillo Chico y que pudo haber tenido múltiples funciones, no solo como ofrenda funeraria asociada quizás a un personaje que ocupaba el edificio. Quien elaboró el modelo en cerámica respetó las proporciones y el orden jerárquico de los recintos, la orientación de los muros entre sí, la secuencia espacial y finalmente la individualidad del edificio como hecho arquitectónico, aun cuando todo esto era difícil de percibirse de una sola vez debido a su ubicación y tamaño. El modelo arquitectónico en cerámica representaría uno de los más emblemáticos de la sociedad chancay: el edificio con rampa, pero al mismo tiempo, podría ser compartido por la tradición de la Costa Central y, al ser transportable, pudo haber sido comparado con otros similares o, en todo caso, usado de referencia previa a cualquier construcción.

\section{RESULTADOS Y DISCUSIÓN}

A partir de los diferentes registros de campo se han obtenido datos inéditos sobre algunos principios en la organización espacial de la arquitectura y sobre sus componentes esenciales: los ejes para el ordenamiento cosmológico inicial y los muros en tanto dimensión semántica respectivamente.

Todas las observaciones desarrolladas parten considerando a la arquitectura e indudablemente sus dimensiones estéticas dentro de la sociedad que la concibe, como parte integrante de dicha cosmovisión, propia e inteligible, al menos por la comunidad en la que existe. De esta manera, es necesario asociarla con la estructura ideológica vigente, en este caso con el idioma, la religión y otras categorías culturales que hoy quizás se aprecian por separado, pero que en su momento se relacionaban profundamente a partir de una cosmovisión andina. Así, se entiende la arquitectura como un sistema integral, en el cual un aspecto importante de su finalidad está referido a la construcción de la memoria. El primer punto es identificar el orden espacial, es decir, la forma en la que se pudo haber subdividido, o mejor, cómo se organizaron los asentamientos y la arquitectura.

Desde la etnohistoria hay avances en el acercamiento a la comprensión de las diferentes formas de organización: espacial, temporal o social, que justamente son las dimensiones con las que interactúa la arquitectura. En general se refieren a los criterios de dualidad, tripartición o cuadripartición y sus posibles formas de combinación. Por ejemplo, según Zuidema, la división triádica es recurrente en la antigua sociedad andina y entre las variadas formas existían:

a) Collana (para referirse al primero, el principal o el jefe), payan (quien tiene el carácter de segundo) y cayao (implica una connotación de origen, se refiere a la base, los fundamentos y las raíces);

b) Capac (término que denota riqueza o realeza), hatun (asociado al significado de grande y numeroso) y huchuy (pequeño);

c) Allauca (derecha), chaupi (en el centro) e ichoc (izquierda).

A esta división se le contrapone otra, binaria o bipartita, entre las que destacan saya-suyu, referido al espacio vertical-masculino y horizontal-femenino respectivamente, o hanan-hurin, entendidos como arriba y abajo (Zuidema 1989: 221-230).

Como resultado de ambas la división resultante es de seis. Esta división es la misma que aparece en los registros de los edificios, como los seis grandes nichos cúbicos en el muro central del edificio de La Bandurria misma; e incluso duplicando su valor a 12 cuando se trata de los lados de la forma geométrica en los nichos escalonados.

Por lo tanto, se han identificado los siguientes componentes como indicadores de análisis arquitectónico y, por su recurrencia o especial diseño, serían expresiones de una estética, de una sensibilidad, materializada en la arquitectura: 
Tabla 1. Resumen de tratamientos estéticos en los muros de edificios chancay. Table 1. Summary of aesthetic treatments of walls in chancay buildings.

\begin{tabular}{l|c|c|c|c|c|c|c}
\multicolumn{7}{c}{ TRATAMIENTOS ESTÉTICOS MURARIOS CHANCAY } \\
\hline & GRAFITIS & RELIEVES & VOLADIZOS & VANOS & ALMENAS & ENLUCIDOS & PINTURAS \\
\hline Pisquillo Chico & & & $\mathrm{X}$ & $\mathrm{X}$ & & $\mathrm{X}$ & \\
\hline La Bandurria & $\mathrm{X}$ & & & $\mathrm{X}$ & & & \\
\hline Pancha La Huaca & & & $\mathrm{X}$ & $\mathrm{X}$ & & & \\
\hline Macatón & $\mathrm{X}$ & & & & & $\mathrm{X}$ & \\
\hline Troncocal & & & & & & $\mathrm{X}$ & \\
\hline Laure & & & & & & $\mathrm{X}$ \\
\hline Hualmay & $\mathrm{X}$ & $\mathrm{X}$ & & & & $\mathrm{X}$ & \\
\hline Cerro Colorado & & & & & & \\
\hline Guarabí & & & $\mathrm{X}$ & & & \\
\end{tabular}

1) Existen dos tipologías de edificios asociados a la cultura Chancay: "edificio con rampa central" y "residencia de élite con nichos". En cada caso, rampa y nichos fueron elaborados, además de su sentido funcional, con un manejo sensible, en donde su ubicación, su forma, su dirección, su organización y cantidad expresarían un mensaje por decodificar. Sobre todo la rampa central, que por sus proporciones con cierta esbeltez, produce un acento de ascensión y tranquilidad. En los nichos hay una apuesta por el efecto de profundidad.

2) Elementos arquitectónicos: además de las rampas y los nichos señalados, están presentes las plataformas como un sistema de jerarquías en sentido vertical, los voladizos como un manejo horizontal de líneas de sombra que identifican el muro, o las gradas de contención que permiten enfatizar ciertas secuencias y un efecto vibrado en la volumetría, de tal manera que, en cada caso, acentúan el carácter del recinto: funcional, perceptual y simbólico.

3) Se han identificado distintas formas de "decoraciones" chancay (tabla 1): relieves, enlucidos, grafitis, etc. Teniendo en cuenta su presencia, su utilización en el sentido más que funcional, perceptual, o su ubicación dentro del soporte, o conformando conjuntos para definir recintos precisos, se puede identificar una lógica estética aplicada a la arquitectura chancay, característica que puede extenderse a distintos niveles, desde el diseño del edificio en general, pasando por sus soluciones constructivas hasta los detalles de su decoración.

\section{CONCLUSIONES}

Los casos revisados permiten sugerir la existencia de una estética de la arquitectura chancay que, obviamente, comparte características significativas con las sociedades andinas coetáneas, así como con el resto de sus propias manifestaciones culturales.

La arquitectura se presenta para las antiguas sociedades como un soporte social, que incorpora una serie de conocimientos generales (tecnológicos, sociales o ecológicos) y otros específicos que hacen referencia a la construcción de una propia estilística: organización espacial (tipos o patrones), elementos arquitectónicos y "decorativos". En el orden particular, a partir de la organización espacial de sus principales patrones arquitectónicos, como los "edificios con rampa", se postula la existencia de "principios de diseño chancay":

1. Simetría yanantin: presencia clara de líneas, muros o ejes ceque que ordenan el trazo y diseño especular, de tal manera que se enfatiza la idea de paridad y su alineamiento con relación al contexto.

2. Inversión del orden cuti: un modelo espacial es rebatido a partir de un eje en su sentido opuesto, y tendría una connotación de temporalidad y regeneración.

3. Dualidad hanaq-hurin y tripartición: presencia constante de dos elementos jerarquizados pero relacionados simbólicamente: patio-rampa-plataforma, o la subdivisión recurrente del edificio en tres unidades arquitectónicas (dos iguales y una diferente), siendo clara la idea de complementariedad. 
4. Alternancia y ritmo: se refiere a la colocación secuencial de elementos señalando periodos espaciales que son al mismo tiempo módulos (también temporales) y que implican su contabilidad.

5. Profundidad: la mayoría de los espacios presentan un énfasis longitudinal a partir de una percepción frontal, que sugiere un énfasis en el enfoque visual, que al mismo tiempo es parte de la concepción del paisaje.

6. Repetición: es la estrategia del uso recurrente del modelo (rampa, nichos o relieves) que genera cierta pregnancia social, de tal manera que es parte de la construcción de la memoria.

7. Luz-sombra y lleno-vacío: manejo consciente y calculado del contraste que se regula en el manejo de los vanos o nichos básicamente.

De esta forma, existen elementos diagnósticos propios que permiten identificar los rasgos de la sociedad chancay. La arquitectura se presenta como un sistema simbólico codificado socialmente y los diferentes elementos reconocidos constituyen partes de una textualidad. Finalmente, la arquitectura presenta condiciones estéticas que pueden ser leídas en clave espacial y simbólica. La sociedad chancay desarrolló un tipo de arquitectura sugerente, a partir de la cual se puede evidenciar un sistema de creación estética propio de una cultura andina en directa relación con el mar, con el valle o con el desierto. A los textiles, cerámica y contextos funerarios reconocidos, se integra ahora un corpus arquitectónico que, en el fondo, hace referencia a la lógica de convivencia cotidiana y ritual, y la arquitectura sirve constantemente para expresar una serie de sentimientos complejos referidos a las visiones propias del devenir entre la vida y la muerte que es, un poco, el deseo inasible por consolidar la memoria: desde los rituales, los espacios y los muros y sus especiales tratamientos.

Agradecimientos Al licenciado Carlos Albino Paucar por compartir sus ideas sobre los grafitis chancay y proporcionarnos información necesaria. Al licenciado Jorge Rodríguez Morales por facilitarnos información. Finalmente, a nuestro amigo Antonio Bazán, del Museo Arqueológico de Huaral, por permitirnos ingresar a su museo y registrar interesantes piezas chancay.

\section{NOTAS}

${ }^{1}$ La base de esta investigación fue presentada en el I Congreso Internacional de Arte Peruano, realizado en la Facultad de Letras y Ciencias Humanas de la Universidad Nacional Mayor de San Marcos, entre el 25 y el 27 de octubre de 2017. El presente trabajo desarrolla nuevas ideas e información inédita sobre la estética chancay y su trascendencia en la arquitectura, a partir de casos específicos, pero al mismo tiempo se sustenta en el marco teórico que desarrolla uno de los autores (Guzmán) en su tesis para optar el grado de Doctor en Ciencias Sociales, UnMsm: "Los símbolos del formativo en los Andes Centrales".

${ }^{2}$ Por ejemplo, Paternosto estudia la propia materialidad de la arquitectura inca desde una visión contemporánea, y observa un despliegue estético ligado a la tectónica inherente en la fábrica, pero además, un agregado calculado en diferentes detalles. Correlaciona ciertas expresiones antiguas con evidentes características abstractas con obras de artistas de las vanguardias de inicios del siglo xx. (Paternosto 1989) Se puede revisar también un artículo del autor, "La abstracción en el arte prehispánico" (Guzmán 1998).

${ }^{3}$ Se trata de dos formas diferentes de concebir el mundo, el de la imagen frente al de la escritura. Así mismo, Lauer señala que desde "entonces palabra e imagen, decir y mostrar han ocupado lugares distintos y jerarquizados en el sistema de símbolos y valores de la cultura peruana, y han constituido en sus relaciones una de las grandes líneas divisorias de la nacionalidad" (Lauer 1975: 10).

${ }^{4}$ Siguiendo a Acha, se ha evitado mencionar los diferentes objetos producidos por las sociedades pre-"industriales" como objetos artísticos. Acha distingue la producción de objetos diacrónicamente como artesanales, artísticos y diseñados, cada uno con un sistema productivo especializado y con sus propias cualidades estéticas (Acha 1990).

${ }^{5}$ Al mismo tiempo se publicó un catálogo-libro, cuya curaduría estuvo a cargo de Polar (1998).

${ }^{6}$ Asumimos la existencia de un sistema de pensamiento en aquellas antiguas sociedades en virtud de la presencia indiscutible de obras materializadas formalmente, donde se advierten diferentes grados de complejidad en los diseños. Y el término andino, construcción contemporánea, si bien muchas veces controvertido, aquí es entendido como territorio, como transcurso y como trayectoria social. Flores Galindo señala que lo andino antes que nada es una "antigua cultura que debería ser pensada en términos similares a los que se utilizan con los griegos, los egipcios o los chinos, pero para ello hace falta que este concepto por crear se desprenda de toda mitificación" (Flores 1987: 12). Depaz también señala que en "este peculiar espacio surgieron distintas culturas que en activa interrelación constituyeron una matriz civilizatoria común cuya continuidad histórica legitima el uso del término 'andino' en el plano cultural" (Depaz 2015: 22). Asimismo, Quiroz indica que el "pensamiento andino [sería] 
el modo particular de la sociedad andina de racionalizar y conceptualizar la realidad, el cual hunde sus raíces en la era prehispánica" (Quiroz 2011: 14).

${ }^{7}$ Ver por ejemplo el estudio de Villanueva sobre los "frisos" en bajorrelieve ubicados en los muros del sitio Huaycán de Cieneguilla, enel que postula una regularidad en el ordenamiento y una combinación de íconos con una posible relación de carácter astronómico, los cuales podrían ser leídos por los especialistas (Villanueva 2014).

${ }^{8}$ Se ha propuesto el término edificio con rampa en lugar de pirámide con rampa el cual se refiere a una forma poliédrica regular y está asociado arqueológicamente a un patrón reconocible de la sociedad egipcia ("pirámides" de función funeraria). El término pirámide fue introducido a inicios de la década de 1960 (Jiménez 1962) para designar a 15 conjuntos de edificios existentes en Pachacamac. La denominación pirámides con rampa (sintetizada en las publicaciones arqueológicas con sus iniciales “PCR”) siguió usándose sin mayor análisis o crítica. Tampoco es correcto el uso de plataforma con rampa pues, como hemos explicado, el objeto de nuestro estudio no es un simple elemento formal o constructivo, sino una definición cultural, compleja y significativa y, si se estudia desde su dimensión arquitectónica, entonces el término es el de edificio. El edificio con rampa existe en los valles de Lurín, Rímac, Chancay y Huaura, surgiendo durante el Horizonte Medio y desarrollándose durante el Intermedio Tardío, estableciéndose posibles relaciones entre las sociedades chancay e ichma. Sobre una discusión de la sociedad ichma se puede consultar a Eeckhout (2004).

${ }^{9}$ Según representación arquitectónica de un modelo de cerámica chancay se observan pequeños recintos elevados con techos inclinados contiguos a patios. Ver la publicación de Wurster 1982.

${ }^{10}$ Para una discusión similar se puede revisar el librocatálogo Modelando el mundo. Imágenes de la arquitectura precolombina (Pardo 2011), en el cual se analiza e interpreta las posibles funciones y finalidades de las "maquetas". En general, la mayoría de los autores apuesta por concebirlas como un modelo simbólico posterior de los edificios.

${ }^{11}$ Sin embargo, recientemente Shady (2018), ha registrado el hallazgo de lo que ha denominado una maqueta, es decir, la configuración formal de diferentes edificios organizados a escala, ubicada a manera de una gran escultura, dentro de un recinto de dimensiones considerables (de unos 5 x $5 \mathrm{~m}$ aproximadamente) en uno de los sitios en proceso de excavación en el valle de Supe para el Período Formativo Inicial, y afirma que sería la elaboración de un diseño anterior, una prefiguración, que implica la planificación de la arquitectura.

${ }^{12}$ La pieza se ha elaborado por técnica de modelado, cocida en ambiente oxidante y con acabado de pintura post cocción en un claro estilo negro sobre blanco, lo cual evidenciaría su asociación estilística con Chancay, aunque no posee contexto de sitio de origen.

\section{REFERENCIAS}

AcHA, J. 1990. Introducción a la teoría de los diseños. México DF: Trillas.

Agurto, S. \& Sandoval, A. 1974 Ms. Inventario, catastro y delimitación del patrimonio arqueológico del valle del río Chancay. Lima: Instituto Nacional de Cultura.

Alvino, J. 2013. Arquitectura chancay. Conjuntos de edificios con rampa central. Investigaciones Sociales 30: 155-178.

Alvino, J. \& Guzmán, M. 2016. Arqueología, arquitectura y arte en Caqui, provincia de Huaral, Lima. Devenir 3 (6): 143-162.

Bonavía, D. 1974. Ricchata quellcani. Pinturas murales prehispánicas. Lima: Fondo del Libro del Banco Industrial del Perú.

Campana, C. 2006. Chan Chan del Chimo. Lima: Orus.

Castillo, L., Nelson, A. \& Nelson, C. 1997. "Maquetas" mochicas. San José de Moro. Arkinka 22: 120-128.

Cornejo, M. 1999. La sociedad prehispánica chancay a través de la muerte. Boletín de Lima XxI (118): 27-44.

De Lavalle, J. \& Lang, W. 1990. Culturas Precolombinas. Chancay. Lima: Banco de Crédito del Perú.

Depaz, Z. 2015. La cosmo-visión andina en el Manuscrito de Huarochirí. Lima: Vicio Perpetuo Vicio Perfecto.

Eecknout, P. (Ed.) 2004. Arqueología de la costa central del Perú en los Periodos Tardíos. Volumen 3. Lima: Instituto Francés de Estudios Andinos.

EsPINOZA, P. 2014. La pirámide B del Complejo Arqueológico Mateo Salado: Investigaciones recientes y restauraciónconservación. Arkinka 219: 100-108.

Flores, A. 1987. Buscando un inca: identidad y utopía en los Andes. Lima: Instituto de Apoyo Agrario.

Franco, R. 1993. Excavaciones en la Pirámide con rampa n 2, Pachacamac. Tesis de Licenciatura en Arqueología. Lima: Universidad Nacional Mayor de San Marcos.

Franco, R., GÁlvez, C. \& VÁsquez, S. 2001. Graffiti mochicas en la huaca Cao Viejo, Complejo El Brujo. Bulletin de l'Institut Français D'études Andines 30 (2): 359-395.

Guzmán, M. 1998. La abstracción en el arte prehispánico. Arquitextos 8: 24-32.

Guzmán, M. 2015. Arquitectura Chancay. El tinkuy en la organización espacial. Arqueología y Sociedad 30: 9-25.

Guzmán, M. 2016. Arquitectura chancay. Espacios rituales del tiempo sagrado. Lima: Editorial Universitaria Universidad Ricardo Palma.

Horkheimer, H. 1963. Chancay prehispánico: diversidad y belleza. Revista Cultura Peruana xxIII (175-178): 62-69.

Horkheimer, H. 1965. Identificación y bibliografía de importantes sitios prehispánicos del Perú. Arqueológicas 8.

JiméneZ, A. 1962. El Conjunto Arqueológico de Pachacámac. En Informe sobre los sitios arqueológicos de Lima, pp. 27-32. Lima: Junta Deliberante.

JiméneZ, A. 1985. Pachacamac. Boletín de Lima 38: 40-54.

KAmpen, M. 1978. The graffiti of Tikal, Guatemala. Estudios de Cultura Maya 6: 155-180. 
KrZANOwsKi, A. (Ed.). 1991. Estudios sobre la cultura Chancay, Perú. Cracovia: Jagiellonian University.

Lauer, M. 1975. Szyszlo. Indagación y collage de Mirko Lauer con ensayos de Javier Sologuren y E. A. Westphalen. Lima: Mosca Azul.

LAVALLE, J. \& LANG, W. 1982. Culturas precolombinas: Chancay. En Arte y tesoros del Perú. Lima: Banco de Crédito del Perú.

Ludeña, W. 1997. Ideas y arquitectura en el Perú del siglo XX. Lima: SEMSA.

LudeÑA, W. 2001. Arquitectura. Repensando a Vitruvio y la tradición occidental. Lima: Universidad Nacional de Ingeniería, Facultad de Arquitectura, Urbanismo y Artes, Instituto de Investigaciones.

Negro, S. 1991. Arquitectura y sistemas constructivos en los asentamientos de la cultura Chancay. En Estudios sobre la cultura Chancay, Perú, A. Krzanowski, Ed., pp. 57-81. Cracovia: Jagiellonian University.

PARdo, C. (Ed.). 2011. Modelando el mundo. Imágenes de la arquitectura precolombina. Lima: Museo de Arte de Lima.

Paternosto, C. 1989. Piedra abstracta. La escultura inca: una visión contemporánea. Buenos Aires: Fondo de Cultura Económica.

Polar, C. 1998. Contemporaneidad del arte Chancay. Lima: Museo de Arte de Lima-Cosapi Organización Empresarial.

Praet, E., Byl, S., Eeckhout, P. \& Luján, M. 2017. Evidencias arqueológicas de la conquista hispana y el período de transición halladas por el proyecto Ychsma en el edificio B4 de Pachacamac, valle de Lurín (2016). Haucaypata. Investigaciones Arqueológicas del Tahuantinsuyo 12: 6-22.

Quiroz, V. 2011. El tinkuy postcolonial. Utopía, memoria $y$ pensamiento andino en Rosa Cuchillo. Lima: Fondo Editorial Universidad Nacional Mayor de San MarcosFondo Editorial Facultad de Letras y Ciencias Humanas.
Reiche, M. \& Fung, R. 1956. El castillo de Casma. Cultura Peruana 93.

Romero, C. 1935. La fundación de Chancay. Revista Histórica IX (IV): 381-387.

Ruiz, A. 1982. Arte mural prehispánico en Hualmay. Los Especiales de Huacho 19: 6-8. <https://www.academia. edu/24705115/Arte_Mural_Prehisp\%C3\%A1nico_de_ Hualmay> [consultado: 19-01-2020].

SHady, R. 2018. Trascendencia de la civilización Caral. En III Conferencia Regional de Educación Superior de América Latina y el Caribe (III CRES 2018). Universidad Nacional de Córdoba, Argentina. <https://www.youtube.com/ watch?v=b-MfShKKQcY> [consultado: 24-03-2020].

Silva, F. 2004. Occidente y el mundo andino. En Anuario de Ciencias de la Religión. Las religiones en el Perú de hoy, D. Ortmann, Comp., pp. 137-164. Lima: Fondo Editorial de la UNMSM-CONCYTEC.

Silverman, H. 1987. Una ocupación Nasca 8 en Cahuachi. Gaceta Arqueológica Andina 13: 10-14.

Tarazona, J. 2000. La cultura Chancay. Huaral: Patronato Provincial de Huaral.

VillanueVA, J. P. 2014. ¿Frisos como Tukapu arquitectónicos? Representaciones del tiempo y la cosmovisión en la provincia inca de Pachacamac. En Sistemas de notación inca: quipu y tocapu. Actas del Simposio Internacional, Lima 15-17 de enero de 2009, C. Arellano, Ed., pp. 303-358. Lima: Ministerio de Cultura.

WURSTER, W. 1982. Modelos arquitectónicos peruanos. Ensayo de interpretación. Revista del Museo Nacional XLVi: 253-266.

Zuidema, R. T. 1989. Reyes y guerreros. Ensayos de cultura andina. Lima: Fomciencias. 